\title{
ENRAIZAMENTO DE ESTACAS DE GOIABEIRAS: INFLUÊNCIA DE FATORES FISIOLÓGICOS E MESOLÓGICOS
}

WALTER HENRIQUE DA COSTA JR

Engenheiro Agrônomo

Orientador: Prof. Dr. João Alexio Scarpare Filho

Dissertação apresentada à Escola Superior de Agricultura "Luiz de Queiroz", Universidade de São Paulo, para a obtenção do título de Mestre em Agronomia, Área de concentração: Fitotecnia.

\section{PIRACICABA}

Estado de São Paulo - Brasil

Novembro -2000 
Dados Internacionais de Catalogação na Publicação (CIP)

DIVISÃO DE BIBLIOTECA E DOCUMENTAÇÃO - Campus "Luiz de QueirOz"/USP

Costa Jr, Walter Henrique da

Enraizamento de estacas de goiabeiras : influência de fatores fisiológicos e miesológicos / Walter Henvíique da Costa Jr. - - Piracicaba, 2000.

66 p. : il.

Dissertação (mestrado) - - Escola Superior de Agricultura Luiz de Queiroz, 2000. Bibliografia.

1.Enraizamento 2. Estaca 3. Estiolamento 4. Goiaba 5. Regulador de crescimento vegetal 6. Substrato I. Título

CDD 634.421

Termitida a copia total ou parcial deste doemmento, desde que citada a fonte - O dutor 


\begin{abstract}
À minha amada Kátia, pelo amor, compreensão
e companheirismo em todos os momentos.

Dedico
\end{abstract}

Aos meus pais, Walter e Stella, pelo carinho, incentivo e dedicação durante toda minha vida. 


\section{AGRADECIMENTOS}

Aos professores João Alexio Scarpare Filho e Ricardo Victória Filho, pela orientação, dedicação, auxílio e amizade.

À Escola Superior de Agricultura "Luiz de Queiroz", Universidade de São Paulo, pela possibilidade da realização do curso.

À CAPES , pela concessão da bolsa de estudos.

Aos professores do curso de Pós-Graduação em Fitotecnia, da ESALQ/USP, pelos ensinamentos recebidos.

Aos professores do Departamento de Produção Vegetal, pelos ensinamentos e pelo convívio.

Aos funcionários do Departamento de Produção Vegetal, em especial ao David, pela colaboração na montagem dos experimentos.

Aos engenheiros agrônomos Victor Branco de Araújo e Paulo Sérgio da Cruz Abrantes do Núcleo de Produção de Mudas de Tietê (SP), pela colaboração, fornecimento do material e da estrutura necessária para a montagem dos experimentos.

Ao engenheiro agrônomo João Carlos de Oliveira, pelo fornecimento dos reguladores vegetais utilizados nos experimentos.

Aos colegas do curso de Pós-Graduação, pelo convívio e companheirismo.

A todos aqueles que de alguma forma contribuíram para o desenvolvimento deste trabalho.

A Deus, que sempre iluminou os meus caminhos. 


\section{SUMÁRIO}

Página

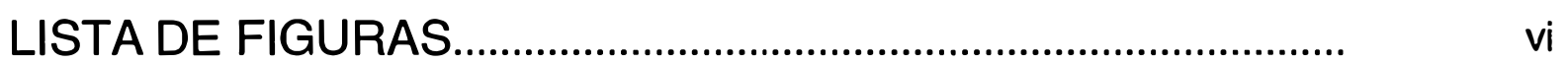

LISTA DE TABELAS.............................................................. vii

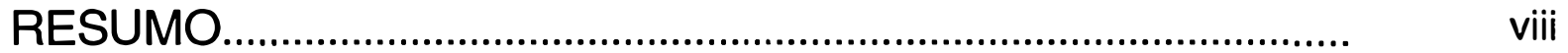

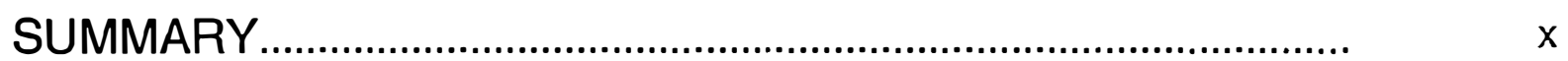

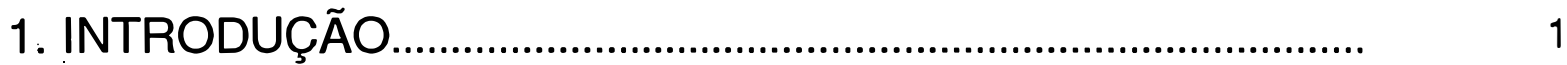

2. REVISÃO DE LITERATURA …................................................ 2

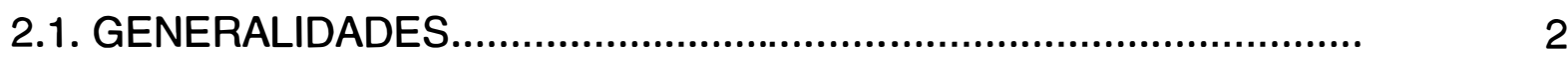

2.2. BASES ANATÔMICAS DO ENRAIZAMENTO..................................

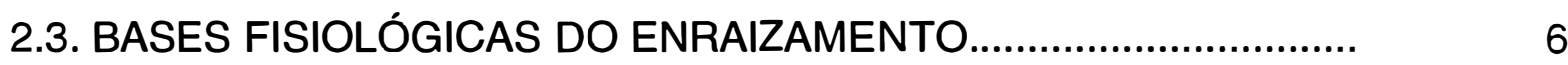

2.4. FATORES QUE AFETAM O ENRAIZAMENTO............................... 10

2.4.1. ESTIOLAMENTO DA PLANTA ...................................................... 14

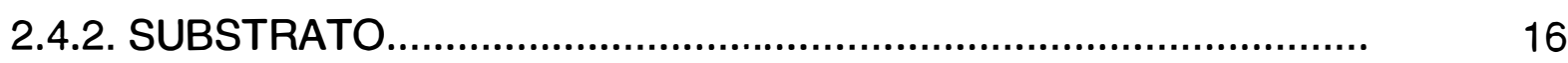

3. EFEITO DO ESTIOLAMENTO NA PLANTA MATRIZ E DO USO DE ÁCIDO INDOLBUTÍRICO NO ENRAIZAMENTO DE ESTACAS DE GOIABEIRAS..................................................... 19

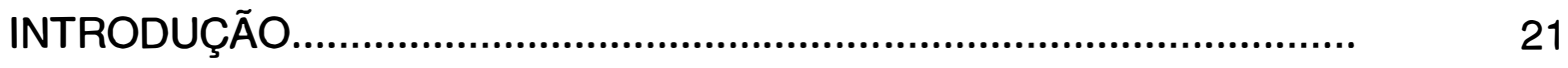

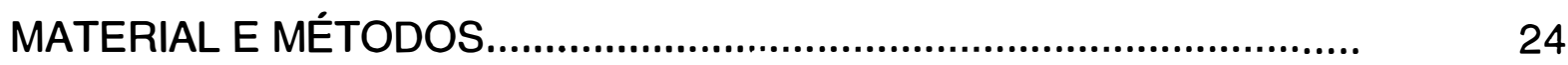

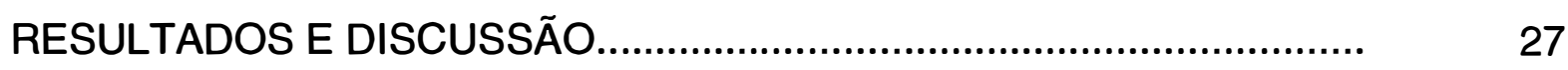

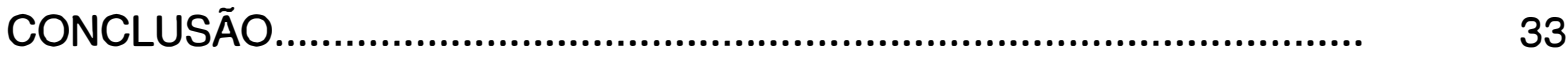

REFERÊNCIAS BIBLIOGRÁFICAS.................................................. 36

4. ENRAIZAMENTO DE ESTACAS SEMI-LENHOSAS DE GOIABEIRA ‘KUMAGAI’ EM FUNÇÃO DO SUBSTRATO E

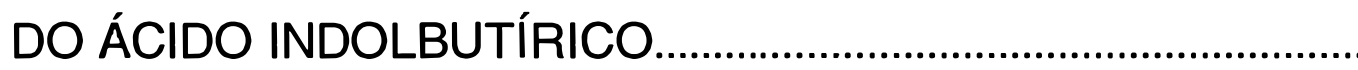




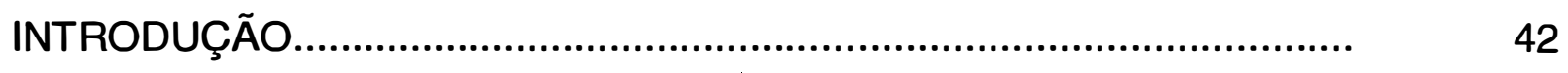

MATERIAL E MÉTODOS.................................................................. 45

RESULTADOS E DISCUSSÃO.......................................................... 48

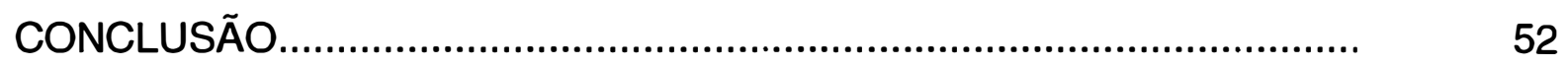

REFERÊNCIAS BIBLIOGRÁFICAS.................................................. 55

5. CONCLUSÕES GERAIS....................................................... 59

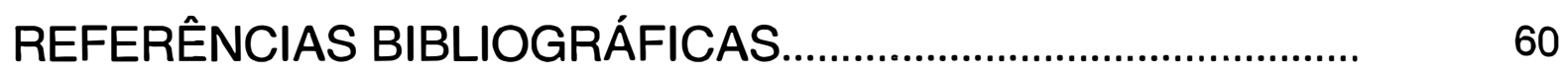




\section{LISTA DE FIGURAS}

Página

1 A - Estacas de goiabeira 'Rica' sob $0 \%$ de sombra, tratadas ou não com IBA; B - Estacas de goiabeira 'Rica' sob $50 \%$ de sombra, tratadas

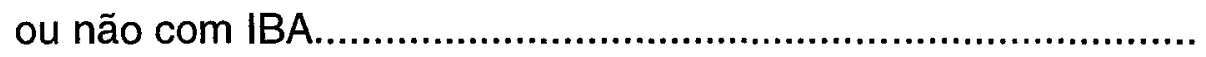

2 A - Estacas de Goiabeira 'Kumagai' sob $0 \%$ de sombra, tratadas ou não com IBA; B - Estacas de Goiabeira 'Kumagai' sob 50\% de sombra, tratadas ou não com IBA.............................................

3 Regressão polinomial dos dados de percentagem de enraizamento, de estacas herbáceas de goiabeira 'Kumagai', em função da concentração de ácido indolbutírico (IBA) em diferentes substratos........ 


\section{LISTA DE TABELAS}

Página

1 Efeito do sombreamento e da aplicação de diferentes concentrações de IBA na porcentagem de enraizamento de estacas semi-lenhosas de

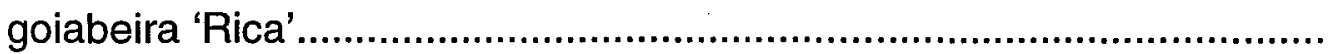

2 Efeito do sombreamento e da aplicação de diferentes concentrações de IBA na porcentagem de enraizamento de estacas semi-lenhosas de goiabeira 'Kumagai'

3 Efeito do sombreamento e da aplicação de diferentes concentrações de IBA no número de raízes de estacas semi-lenhosas de goiabeira 'Rica'.

4 Efeito do sombreamento e da aplicação de diferentes concentrações de IBA no número de raízes de estacas semi-lenhosas de goiabeira 'Kumagai'

5 Características físicas e químicas dos substratos..................................

6 Efeito de diferentes concentrações de IBA e do substrato, na percentagem de enraizamento de estacas semi-lenhosas de goiabeira 'Kumagai'

7 Efeito de diferentes concentrações de IBA e do substrato no número de raízes de estacas semi-lenhosas de goiabeira 'Kumagai'..... 


\title{
ENRAIZAMENTO DE ESTACAS DE GOIABEIRAS:
}

\section{INFLUÊNCIA DE FATORES FISIOLÓGICOS E MESOLÓGICOS.}

\author{
Autor: Walter Henrique da Costa Jr. \\ Orientador: Prof. João Alexio Scarpare Filho
}

\section{RESUMO}

Com o objetivo de estudar a influência dos fatores fisiológicos e mesológicos do enraizamento de dois cultivares de goiabeira foram realizados dois experimentos. No primeiro experimento, plantas matrizes de goiabeira, dos cultivares Rica e Kumagai, foram submetidas ao estiolamento visando verificar a influência desta técnica no enraizamento de estacas. Adotou-se o delineamento estatístico de blocos ao acaso, em fatorial $2 \times 3$, onde os fatores estudados foram concentração de IBA, em dois níveis ( 0 e $\left.2000 \mathrm{mg} \cdot \mathrm{L}^{-1}\right)$, e sombreamento, em três níveis $(0,30$ e $50 \%)$. As estacas foram colocadas para enraizar em câmara de nebulização. Após 60 dias, foram avaliadas a porcentagem de estacas enraizadas, o número de raízes por estaca, a porcentagem de estacas mortas e de estacas com gemas brotadas. Os cultivares testadas possuem diferentes capacidades de enraizamento. Para o cultivar Kumagai a utilização de $30 \%$ de sombreamento proporcionou os melhores resultados de enraizamento. Para o cultivar Rica, a utilização de $30 \%$ de sombreamento na planta matriz, ou a aplicação de $2000 \mathrm{mg} \cdot \mathrm{L}^{-1}$ de IBA na estaca, proporcionaram as maiores percentagens de estacas enraizadas. A utilização de ácido indolbutírico aumentou o número de raízes formadas para os 2 cultivares. $O$ estiolamento aumentou 0 número de raízes formadas para o cultivar Rica, enquanto que para 'Kumagai', não influenciou o número de raízes formadas. $O$ segundo experimento teve como objetivo verificar a influência do ácido indolbutírico (IBA) e do substrato no 
enraizamento de estacas semi-lenhosas de goiabeira 'Kumagai' (Psidium guajava L.). As estacas foram submetidas às concentrações de zero, 2000, 4000, e 8000 mg. $L^{-1}$ de IBA, e colocadas para enraizar em bandejas de plástico contendo turfa, vermiculita ou a mistura turfa:vermiculita (1:1), sob nebulização intermitente. Adotou-se o delineamento estatístico de blocos ao acaso, em fatorial $4 \times 3$, totalizando doze tratamentos. Foram utilizadas três repetições, dos diferentes tratamentos, dispostas a acaso, sendo que cada parcela foi composta por 10 estacas. A concentração de IBA que proporciona maior percentagem de enraizamento para a goiabeira 'Kumagai' varia de acordo com $\circ$ substrato. Quando utiliza-se turfa como substrato, a maior percentagem de enraizamento é obtida com a utilização de $5565 \mathrm{mg}^{-L^{-1}}$ de IBA, para vermiculita, o melhor resultado é obtido com a aplicação de $5304 \mathrm{mg} \cdot \mathrm{L}^{-1}$ de IBA, e na mistura turfa e vermiculita, a concentração de $8000 \mathrm{mg} \cdot \mathrm{L}^{-1}$ proporcionou a melhor percentagem de enraizamento. $O$ número médio de raízes por estaca aumentou à medida que aplicou-se uma maior concentração de IBA nas estacas. A aeração e o pH foram atributos dos substratos que influenciaram no enraizamento de estacas. 


\section{ROOTING OF GUAVA CUTTINGS: EFFECT OF PHYSIOLOGIC AND MESOLOGIC FACTORS.}

Author: Walter Henrique da Costa Jr. Adviser: Prof. João Alexio Scarpare Filho

\section{SUMMARY}

Two experiments were conducted with the main objective to verify the influence of physiologic and mesologic factors on the rooting of two guava cultivars. In the first experiment, stock plants of two guava cultivars were submitted to shading with the aim of verifying the technical influence of this technique in the rooting of cuttings. It was used the shading of stock plants with the percentage of 30 and $50 \%$, as stock plants growing with plenty of sun. The cuttings were treated or not with $2000 \mathrm{mg} \cdot \mathrm{L}^{-1}$ and put to root in a green house. After 60 days, the percentage of rooted cuttings were evaluated, as the number of roots per cutting, the percentage of dead cuttings and the percentage of shooted cuttings. The 'Rica' and 'Kumagai' cuttings have different rooting capabilities. The use of $30 \%$ of shading in the 'Kumagai' provided the best results of rooting, but for 'Rica', $30 \%$ shading of stock plants or the application of $2000 \mathrm{mg}^{-1}$ IBA in the cuttings, provided the best percentages of rooting. The use of indolebutyric acid increases the number of roots in the cuttings of both cultivars. Though the shading increases the number of roots for 'Rica' cuttings does not have influence over the number of roots of 'kumagai' cuttings. The second research has as the main objective to verify the influence of indolebutyric acid and of the substract on the rootting of semi-hardwood 'Kumagai' guava cuttings. The cuttings were submitted to concentrations of zero, $2000,4000,8000 \mathrm{mg}^{-\mathrm{L}^{-1}}$ of IBA, and put to root on plastic trays with peat, vermiculite or a peat:vermiculite (1:1) mixture, under intermittent 
nebulization. After 60 days, the percentage of rooted cuttings were evaluated, as the number of roots per cutting, the percentage of dead cuttings and the percentage of shooted cuttings. The ideal concentration of indolebutyric acid varies according to the substract. Peat, vermiculite and peat:vermiculite (1:1) mixture have the best results with $5565 \mathrm{mg} \cdot \mathrm{L}^{-1}, 5304 \mathrm{mg} \cdot \mathrm{L}^{-1}$ and $8000 \mathrm{mg} \cdot \mathrm{L}^{-1}$ respectively. The average number of roots increases as the concentration of IBA applied in the cuttings raised. Aeration and $\mathrm{pH}$ were attributes that had influence on the rotting of cuttings. 


\section{INTRODUÇÃO}

$\mathrm{Na}$ década de 60 , os primeiros pomares comerciais de goiabeiras foram formados a partir de mudas obtidas diretamente de sementes, que embora fossem de baixo custo, apresentavam elevada heterogeneidade no porte e na produtividade das plantas, bem como na qualidade dos frutos (Pereira et al., 1983).

A obtenção de mudas através de enxertia, foi adotada nas regiões que cultivam esta fruteira para o mercado de frutos "in natura", permitindo a formação de mudas de variedades selecionadas de acordo com a qualidade exigida pelo mercado.

$\mathrm{Na}$ enxertia da goiabeira utilizam-se as técnicas de borbulhia e de garfagem, retirando-se borbulhas ou garfos de matrizes que produzam frutos de características superiores. A utilização da enxertia na propagação da goiabeira resolveu o problema da variabilidade genética, mas as mudas obtidas por este método, além de exigir mão de obra especializada, permanecem por um período longo no viveiro, o que consequentemente eleva seu custo.

À partir da década de 80 , intensificaram-se os estudos na produção de mudas de goiabeira por estaquia, proporcionando mudas de custo mais baixo. Entretanto, neste método de propagação de goiabeiras são encontradas algumas dificuldades. A percentagem de enraizamento de alguns cultivares é muito baixa, necessitando da otimização dos fatores envolvidos no enraizamento para que se obtenha maior sucesso. 
O objetivo deste trabalho é observar o efeito dos fatores: estiolamento, concentrações de reguladores de crescimento e diferentes substratos no enraizamento de estacas de dois cultivares de goiabeira.

\section{REVISÃO DE LITERATURA}

\subsection{Generalidades}

A goiabeira, Psidium guajava L., é uma planta da família Mirtaceae, encontrada facilmente devido à grande facilidade de disseminação de suas sementes por aves e mamíferos. É sem dúvida uma planta nativa da América tropical, uma vez que todas as mais de cem espécies do gênero Psidium são originárias da América (Medina, 1991). De acordo com Hoehne (1946) a primeira citação à goiaba no Brasil foi feita por Gabriel Soares de Souza em seu "Tratado Descritivo do Brasil".

Os principais países produtores de goiaba são: Brasil, Tailândia, Quênia, Antilhas Francesas, África do Sul, Índia e Paquistão. Starling (1990), afirma que o Brasil é o principal fornecedor de goiaba para o mercado europeu, sendo que é o único país que oferta $\circ$ produto ao longo de todo 0 ano, enquanto seus concorrentes oferecem somente no período de março a setembro.

O mercado mundial de goiaba, aparentemente, ainda não foi adequadamente quantificado. Maia et al. (1991) observaram que levantamentos efetuados em publicações de órgãos oficiais apontam uma grande "escassez e desatualização de dados sobre a produção mundial de goiaba".

De acordo com o Ministério da Agricultura, a safra brasileira de 1997/98 foi de 230 mil toneladas, sendo que São Paulo se destacou como principal produtor, 
participando com 130 mil toneladas. Os pomares paulistas possuem cerca de 950 mil plantas, mas segundo a Goiabrás (Associação Brasileira de Produtores de Goiaba) $50 \%$ destas arvores já entraram em declínio, e deveriam ser substituídas por cultivares geneticamente mais produtivas e resistentes.

No estado de São Paulo, os principais municípios produtores são Taquaritinga, Itápolis, São Carlos, Urupês e Monte Alto, onde predomina a produção de goiaba para a indústria. A produção de goiaba para mesa é concentrada nos municípios de Mirandópolis, Valinhos e Mogi das Cruzes.

Os primeiros pomares foram formados na década de $60 \mathrm{com}$ mudas obtidas à partir de sementes, que embora fossem de baixo custo, apresentavam variação no porte, na produtividade das plantas, e na qualidade dos frutos (Pereira et al., 1983).

Estes problemas foram solucionados com a implantação de novos pomares através da propagação vegetativa da goiabeira. Este método permite a formação de pomares uniformes e altamente produtivos, cujos frutos apresentam padrões definidos que possibilitam sua comercialização como fruta fresca e a elaboração de conservas padronizadas com ampla aceitação no mercado consumidor.

A obtenção de mudas através de enxertia, foi adotada nas regiões que cultivam esta fruteira para o mercado de frutos "in natura", para proporcionar a formação de mudas de variedades selecionadas cujos frutos apresentem características organolépticas que satisfaçam as necessidades do mercado.

Embora a enxertia de borbulhas ou garfos de plantas matrizes selecionadas tenha solucionado o problema da variabilidade genética, e permitido a obtenção de cultivares com características superiores, esta prática proporcionou mudas com maior custo e com maior período de permanência no viveiro. (Pereira et al. 1983 e 1991) 
A propagação da goiabeira por estaquia foi estudada mais a fundo na década de 80 , onde foram notadas algumas vantagens como produzir uma muda de qualidade, com um menor período de permanência no viveiro, e consequentemente reduzindo custos.

\subsection{Bases anatômicas do enraizamento}

A formação de raízes adventícias pode ser dividida em duas fases: a iniciação, que consiste na divisão celular e na diferenciação de algumas células em primórdios radiculares, e em uma segunda fase, caracterizada pelo crescimento através da expansão resultante da combinação entre divisão $e$ alongamento celular (Janick, 1966).

Por outro lado Hartmann et al. (1990) dividem a formação de raízes adventícias em quatro fases: Desdiferenciação celular; Formação de primórdios radiculares a partir de células do tecido vascular, as quais se tornaram meristemáticas devido a desdiferenciação; Desenvolvimento dos primórdios radiculares; Emergência das raízes e conexão vascular.

Os primórdios radiculares estão geralmente associados à região nodal, embora possam aparecer em outras regiões, quando utiliza-se estacas.

Na nogueira pecã (Carya illinoensis) a iniciação das raízes ocorre na camada externa do parênquima vascular, cujas células possuem atividade cambial, e são responsáveis pela formação dos primórdios radiculares. Esses primórdios desenvolvem-se e empurram outros tecidos adjacentes, rompendo as células do córtex e exteriorizando as raízes (Fahn, 1974).

Trabalhando com micro estacas de maçã do cultivar gala, Harbage et al. (1993) observaram que apenas as células do parênquima do floema responderam à indução ao enraizamento através da formação de primórdios radiculares, 
embora as células da medula, xilema, câmbio e córtex tenham demonstrado reação à aplicação de auxina, através do aumento da divisão celular.

Observando-se os exemplos citados anteriormente, pode-se concluir que a origem dos primórdios radiculares é portanto característica da espécie.

A facilidade de enraizamento de algumas estacas pode estar ligada à presença de raios vasculares mais largos, como é o caso da Vitis vinifera e da Tamarix spp. Raios mais estreitos como os das plantas dos gêneros Cerotonia, Pyrus e Carya, estão associados ao difícil enraizamento destas plantas (Fahn, 1974).

$\mathrm{Na}$ formação de raízes é comum o aparecimento de calos na base da estaca. O calo é uma massa irregular de células parênquimáticas em vários estados de lignificação. Os calos podem proliferar à partir de células da região do câmbio vascular, na base da estaca, podendo também ter origem nas células da medula e do córtex (Hartmann et al., 1990).

Em estacas caulinares de café o calo se forma através da divisão de células do floema e do câmbio, embora possam ser encontradas células do periciclo, córtex e medula. A formação do calo ocorre antes da iniciação e do desenvolvimento radicular (Vilanova,1959).

Muitos autores concordam que a existência de uma extensa camada de esclerênquima no tecido do floema tem correlação direta com a dificuldade de enraizamento de algumas espécies frutíferas lenhosas (Ono \& Rodrigues, 1996).

Em estacas retiradas de pereira, espécie considerada de difícil propagação por estaquia, uma camada quase contínua de fibras com paredes celulares grossas envolve o floema secundário, que em corte transversal revela a presença de uma camada de tecidos lignificados (Beakbane, 1961).

Tratamentos com auxinas e a manutenção das estacas sob nebulização, favorecem a expansão e proliferação celular no córtex, floema e câmbio, 
resultando na quebra da continuidade do anel de esclerênquima (Hartmann et al., 1990). Em estacas de oliveiras (Olea europaea L.) que apresentam difícil enraizamento, foi observada a presença de fendas no anel de esclerênquima, após 5 semanas do tratamento das estacas com auxina (Fouad et al., 1990).

\subsection{Bases fisiológicas do enraizamento}

A formação de raízes adventícias é um processo de desenvolvimento que envolve uma sequência de mudanças nos tecidos, onde cada estágio possui um diferente requerimento hormonal (auxinas, citocininas, ácido giberélico, etc.). A fase de iniciação pode ser dividida em um estágio inicial de resposta a auxina endógena e exógena, seguido por um estágio onde não ocorre a resposta a este hormônio. A fase de desenvolvimento caracterizada pelo crescimento e elongação das células, e aparecimento de um sistema radicular que se conecta aos vasos da estaca, não apresenta resposta à aplicação de auxina (Hartmann et al., 1990).

Os vegetais superiores apresentam três auxinas sintetizadas naturalmente: IAA, 4-CI-IAA, e IAcrA. O IAA, ou ácido indol-acético, é o mais encontrado, talvez ocorrendo universalmente nas plantas (Gaspar \& Hofinger, 1988).

Vários estudos provaram que algumas substâncias sintéticas tinham efeito análogo às auxinas. Estas substâncias, o IBA (ácido indolbutírico) e o NAA (ácido naftalenoacético), tem sido usadas na promoção do enraizamento em diversos tipos de estacas, de diferentes espécies. O IBA e o NAA tem efeito comprovadamente superior ao do IAA, sendo que o IBA aparentemente é mais efetivo que o NAA. Os sais potássicos de IAA, IBA e NAA, são consistentemente mais efetivos que seus correspondentes ácidos (Blazich, 1988a).

A aplicação de auxinas sintéticas é pratica comum no enraizamento de estacas. Existem vários trabalhos que atestam a influência positiva das auxinas sintéticas, no enraizamento de estacas de espécies consideradas de difícil enraizamento, como a jaboticabeira (Myrciaria cauliflora (Mart.) Berg) e algumas 
cultivares de pessegueiro (Prunus persica (L.) Batsch) e de goiabeira (Duarte et al., 1997; Scarpare Filho, 1990; González \& Schimidt , 1992).

O tipo de auxina utilizada apresenta influência sobre o enraizamento das estacas. De acordo com Gonzáles \& Schimidt (1992), o NAA apresentou performance significativamente inferior à do IBA no enraizamento de estacas de goiabeira 'Kumagai'.

As concentrações de auxinas utilizadas no enraizamento das estacas de goiabeira, assim como os resultados obtidos com suas aplicações disponíveis na literatura apresentam grande variação.

Pereira et al. (1983) utilizando $2000 \mathrm{mg} \cdot \mathrm{L}^{-1}$ de ácido naftaleno acético (NAA) em estacas herbáceas do cultivar $\mathrm{J}-3$, contendo dois nós e dois pares de folhas, obtiveram $70,22 \%$ de enraizamento em condições de nebulização.

González \& Schimidt (1992), estudando o efeito do IBA e do ácido naftaleno acético (NAA) no enraizamento de estacas de goiabeira 'Kumagai', nas concentrações de 1000 e $2000 \mathrm{mg}^{-1} \mathrm{~L}^{-1}$ para o IBA e 5 e $10 \%$ para o NAA, observaram que o IBA promoveu o enraizamento de $25 \%$ das estacas na concentração de $1000 \mathrm{mg} \cdot \mathrm{L}^{-1}$, não apresentando diferença significativa em relação a concentração de $2000 \mathrm{mg} \cdot \mathrm{L}^{-1}$. O NAA não proporcionou o enraizamento de nenhuma estaca, nas concentrações utilizadas.

Para Kersten \& Ibañez, (1993), o incremento nas concentrações de IBA proporcionou um aumento significativo da percentagem de enraizamento de estacas de goiabeira 'Kumagai'. $O$ tratamento das estacas em imersão rápida nas concentrações de 3000,4000 e $5000 \mathrm{mg} \cdot \mathrm{L}^{-1}$, resultou em 25,0, 38,33 e 47,5\% de enraizamento, respectivamente.

Bacarin et al. (1994) constataram que a aplicação de IBA em imersão lenta, na concentração de $100 \mathrm{mg} \cdot \mathrm{L}^{-1}$ proporcionou maior percentagem de enraizamento às estacas do cultivar 'Rica', que $200 \mathrm{mg} \cdot \mathrm{L}^{-1}$. 
O comportamento de estacas de uma mesma espécie pode não ser o mesmo, pois as diferenças muitas vezes ocorrem à nível do cultivar.

Estudando o efeito do ácido indolbutírico (IBA) no enraizamento de estacas de goiabeira dos cultivares Rica e Paluma, Pereira et al. (1991) utilizaram a aplicação de IBA em imersão lenta, nas concentrações de $0,100,200$, e 400 $\mathrm{mg} \cdot \mathrm{L}^{-1}$, na ausência de luz, por um período de 14 horas. Encontraram resultados diferentes para cada um dos cultivares estudadas. A concentração de $200 \mathrm{mg} \cdot \mathrm{L}^{-1}$ mostrou ser a mais eficiente para 'Paluma'. Para o cultivar Rica, os tratamentos com 100 e $200 \mathrm{mg} \cdot \mathrm{L}^{-1}$ apresentaram resultados muito semelhantes.

Tavares et al. (1995) verificaram que estacas retiradas de goiabeiras que produziam frutos vermelhos, apresentavam enraizamento superior, quando comparadas com as de polpa branca.

A capacidade de formação de raízes em estacas é devida a um sinergismo entre fatores inerentes às células e as substâncias transportáveis produzidas nas folhas e gemas. Substâncias como carboidratos, compostos nitrogenados, vitaminas e outros compostos não identificados, tem ação recíproca com a auxina, afetando a formação de raízes, sendo denominadas co-fatores do enraizamento (Janick, 1966).

Um ensaio procurando estudar o efeito de alguns co-fatores no enraizamento de estacas de Vigna unguiculata, constatou que os aminoácidos triptofano em concentrações de 5 a 25 ppm, lisina e ácido glutâmico em concentração de $25 \mathrm{ppm}$, promoveram um aumento na percentagem de enraizamento, e nos níveis de auxinas nas raízes (El-Nabarawy, 1996).

A presença de folhas nas estacas tem um efeito benéfico, atribuído à produção de auxinas e co-fatores de enraizamento, que são transportados para a região basal da estaca (van Overbeek et al., 1946). 
As folhas também são responsáveis por dar continuidade ao processo fotossintético, e fornecer energia para a formação e crescimento radicular, através da síntese de carboidratos (Janick,1966).

A manutenção das folhas é fundamental para o enraizamento de estacas semi-lenhosas de maracujazeiro (Passiflora edulis f. flavicarpa) e abacateiro (Persea americana), entre outras espécies frutíferas (Reuveni \& Ravivi, 1981; Meletti \& Nagai, 1992).

Pereira et al. (1983), objetivando determinar quais os melhores tipos de estacas de goiabeira, concluíram que as retiradas da porção apical dos ramos, dotadas de dois nós e um par de folhas secionadas ao meio, promoveram os maiores percentuais de enraizamento.

Não apenas a presença das folhas é importante. A área foliar pode ter influência na formação de raízes, tanto pela translocação de substâncias como pela perda de água por transpiração.

Na propagação por estaquia semi-lenhosa dos porta-enxertos de videira dos cultivares. 'Jales' e 'Campinas', os autores do trabalho concluíram que a presença da folha nas estacas foi indispensável para a formação de raízes. A variação da área foliar não teve influência na percentagem de enraizamento, mas teve alta correlação com a emissão e crescimento das raízes. O aumento na área foliar foi acompanhado pelo incremento do número de raízes emitidas por estacas até os valores de $91,4 \mathrm{~cm}^{2}$ para o cultivar 'Campinas' e $91,9 \mathrm{~cm}^{2}$ para o cultivar 'Jales' (Biasi et al., 1997).

Estudos realizados em Bangladesh demonstraram que estacas semilenhosas de espécie florestal Azadirachta indica também não sofreram influência da área foliar na percentagem de enraizamento, porém um aumento na biomassa de suas raízes em vasos, foi verificado quando as estacas apresentavam $100 \%$ da área foliar no momento do enraizamento (Kamaluddin \& Ali, 1996). 
Existe um efeito antagônico entre a presença de flores e o enraizamento de estacas. Alguns autores atribuem esse efeito à competição por reservas entre as flores e as raízes adventícias em formação, ou ao fotoperíodo que induz o florescimento e inibe a formação de raízes adventícias. Esta última hipótese foi comprovada por De Vier \& Geneve (1997) em um ensaio em que foram avaliadas estacas de crisântemo (cv. Boaldi) oriundas de plantas sob fotoperíodo indutivo ao florescimento (dias longos) e plantas sob fotoperíodo vegetativo (dias curtos). Foi observado que as porcentagens de enraizamento foram significativamente maiores nas estacas retiradas de matrizes sob dias curtos.

A presença de compostos fenólicos tem grande influência na formação de raízes adventícias. Um estudo comparando as porcentagens de enraizamento de 8 cultivares de oliveira (Olea europaea L.), verificou que uma maior concentração de compostos fenólicos está associada ao cultivar Dermlali, que é considerado como de difícil enraizamento. Entretanto o cultivar Weteken, considerado como de fácil enraizamento, apresentou as menores concentrações destes compostos (Fouad, 1990).

Os compostos fenólicos estão envolvidos diretamente na síntese de lignina e suberina, atuam como co-fatores das auxinas, $e$ como inibidores $e$ estimuladores da IAA oxidase. A relação dos compostos fenólicos com a IAA oxidase varia de acordo com a composição destes fenóis. Os monofenóis podem atuar estimulando a destruição do IAA, enquanto que os polifenóis apresentam efeito sinérgico com o IAA (Haissig, 1986).

\subsection{Fatores que afetam o enraizamento}

Andersen (1986) atenta para o fato de que a temperatura, água, luz e nutrição são fatores que merecem especial atenção na propagação de plantas por estaquia. Entretanto, o comportamento das espécies em relação a influência destes fatores não é o mesmo, ficando difícil adotar considerações generalizadas. 
A interação entre os diversos fatores contribui para dificultar a adoção de parâmetros para cada fator isoladamente, assim como o observado por Moe \& Andersen (1988) que afirmam que a influência da temperatura no enraizamento de estacas pode ser confundida com a atuação de outros atributos ambientais.

Estes fatores podem influenciar o enraizamento das estacas em dois momentos distintos, atuando tanto no período de desenvolvimento dos ramos na planta matriz, quanto na estaquia propriamente dita.

Existe uma interação complexa entre a temperatura e o fotoperíodo na qual a planta matriz se encontra, com os teores de auxinas e outros hormônios. A temperatura do ar do matrizeiro tem aparentemente, um papel secundário na capacidade de enraizamento das estacas, caso as plantas matrizes se encontrem numa faixa de 12 a $27^{\circ} \mathrm{C}$ (Moe \& Andersen, 1988).

Quando aborda-se a temperatura como fator mesológico de influência na propagação por estaquia, deve-se decompor este fator em duas partes: a temperatura da atmosfera; e a temperatura do leito de enraizamento (Janick, 1966).

Temperaturas diurnas na faixa de 21 a $27{ }^{\circ} \mathrm{C}$, associadas com temperaturas noturnas na faixa dos $15{ }^{\circ} \mathrm{C}$, são consideradas ótimas para o enraizamento da maioria das espécies (Hartmann et al., 1990).

A temperatura do ar é bastante influenciada pelo sistema de nebulização, sendo que a temperatura é cerca de $7{ }^{\circ} \mathrm{C}$ inferior nas folhas e $5{ }^{\circ} \mathrm{C}$ inferior no ar, no sistema de nebulização (Loach, 1988).

Quanto ao substrato, temperaturas da ordem de 18 a $25^{\circ} \mathrm{C}$ são suficientes para promover o enraizamento de estacas de espécies de clima temperado, enquanto que espécies tropicais requerem temperaturas até $7{ }^{\circ} \mathrm{C}$ superiores a estes valores (Hartmann et al, 1990). 
A disponibilidade de água apresenta uma influência maior sobre as estacas que na planta matriz. Moe \& Andersen (1988) apontam as controvérsias em relação ao efeito do estresse hídrico nas matrizes, afirmando que a interação deste fator com a irradiância, pode influenciar diretamente no enraizamento, e portanto confundir seus efeitos.

A necessidade de água pelas estacas se fundamenta no fato de que recém colocadas no substrato para enraizar, ainda não possuem raízes e portanto, não tem como absorver água suficiente para compensar a transpiração e o crescimento de novas brotações (Janick, 1966).

A quantidade de água necessária no sistema de propagação pode variar de acordo com o tipo da estaca. Estacas herbáceas e com folhas apresentam maior susceptibilidade á falta d'água que estacas lenhosas. A presença de folhas contribui para as perdas de água pela estaca.

A transpiração das estacas pode ser controlada através da redução da área foliar, através da retirada das folhas basais, ou do corte de folhas pela metade (Preece \& Read, 1993).

Outra forma de reduzir as perdas de água pelas folhas consiste no uso de câmaras de nebulização. Janick (1966) afirma que o uso da nebulização artificial conserva a umidade elevada e reduz a temperatura da folha mantendo uma película de água sobre a mesma, permitindo a realização da estaquia em ambientes de maior luminosidade, não reduzindo a eficiência fotossintética.

Variações qualitativas e quantitativas da luz que incide sobre as plantas matrizes, podem favorecer a síntese inadequada de IAA (ácido indol acético), a inibição de co-fatores para o enraizamento, o aumento da atividade da peroxidase e a formação de barreiras histológicas ao desenvolvimento das raízes adventícias (Hartmann et al., 1990). 
A influência do fotoperíodo no enraizamento é um assunto controvertido. Entretanto existe um consenso em afirmar que o fotoperíodo atua sobre a fotossíntese e consequentemente sobre a produção de carboidratos. Vários autores relacionam os teores de carboidratos nas estacas ao seu enraizamento.

Moe \& Andersen (1988) atentam para o fato de que o fotoperíodo que induz o florescimento aparentemente inibe o enraizamento das estacas.

A influência da qualidade da luz recebida pela planta matriz, no enraizamento das estacas, é atribuída ao comprimento de onda luminosa incidente e à distribuição desta luz pelos ramos da planta. A luz azul parece estimular o enraizamento, bem como a verde, e a luz vermelha $(680 \mathrm{~nm})$ é mais inibitória, quando comparada com as anteriores (Hartmann et al., 1990).

Existem poucos trabalhos relacionando a qualidade da luz com a propagação por estaquia. Morini et al. (1990) utilizando estacas folhosas de oliveira (cv. 'Leccino'), tratadas ou não com 2500 ppm de IBA, e colocadas para enraizar sob 5 diferentes cores de luz, branco, vermelho, amarelo, verde, e azul, verificou que a luz amarela favoreceu uma maior percentagem de enraizamento, um maior número de brotação das estacas, e uma maior retenção das folhas nas estacas. A luz vermelha contribui para aumentar o número de raízes por estaca, embora os resultados obtidos com a luz amarela não sejam significativamente inferiores.

O estado nutricional da planta matriz é um fator a considerar no momento de escolha das estacas. A adubação nitrogenada das plantas matrizes influi mais no enraizamento das estacas que a aplicação de outros macronutrientes, sendo que niveis baixos e médios de $\mathrm{N}$ na planta matriz, implicam em maiores porcentagens de enraizamento, ao contrário do que acontece com a aplicação de doses levadas de nitrogênio (Hartmann et al, 1990).

Blazich (1988b) em revisão feita sobre a influência da nutrição mineral no enraizamento de estacas, relatou que estacas de uva enraizavam mais facilmente, 
aplicando zinco nas plantas matrizes. O zinco é necessário para a produção do triptofano, que é um precursor da auxina. Portanto as aplicações de zinco aumentam os teores de auxina endógena dos ramos, e consequentemente das estacas. $O$ autor também comentou que cultivares de abacateiro que apresentam dificuldade de enraizar estacas, possuem níveis elevados de manganês nas folhas. O manganês é conhecido como ativador da IAA oxidase, que destrói a auxina endógena das estacas, prejudicando o enraizamento.

Além dos fatores mesológicos e nutricionais, na revisão de literatura foi dada atenção especial aos fatores: estiolamento da planta e substratos para propagação, uma vez que são objetos diretos do presente trabalho.

\subsubsection{Estiolamento da planta}

O estiolamento consiste no crescimento de toda a planta, ou de parte dela, sob condições de ausência total ou parcial da luz. A utilização desta prática como método de enraizamento de estacas não é recente, Gardner (1936) descreveu-o como eficiente para cultivares de macieira difíceis de propagar por estaquia.

Hansen (1987) afirma que a exclusão total da luz durante o crescimento das plantas favorece a formação de raízes adventícias em algumas espécies lenhosas.

A falta de clorofila, que caracteriza o estiolamento, aparentemente não influencia no enraizamento, e geralmente o reverdecimento ocorre rapidamente (Maynard \& Bassuk, 1988).

Na propagação por estaquia o estiolamento pode ser feito na planta matriz como um todo, em alguns ramos, ou ainda de forma localizada através da aplicação de uma fita de cor escura na base de ramos que originarão as estacas (Hartmann et al., 1990). 
Os ramos estiolados apresentam diferenças anatômicas que podem favorecer o aparecimento de primórdios radiculares. A formação de tecidos mais tenros, com menor resistência mecânica, se deve a menor presença de lignina, à formação de células com paredes mais finas e à menor suberização dos tecidos externos (Maynard \& Bassuk, 1988).

Maynard \& Bassuk (1996) obsenvaram o aparecimento de fendas no anel de esclerênquima de estacas da ornamental Carpirus betulus L. fastigiata, cujas matrizes foram submetidas a 50,75, 95 e 100\% de estiolamento. O número de fendas aumentou de acordo com 0 incremento na percentagem de sombreamento.

Esta prática também aumenta a sensibilidade dos ramos à auxina, e tem sido relacionada às mudanças em compostos fenólicos que atuam como inibidores da IAA oxidase (Hartmann et al., 1990).

Figueiredo et al. (1995) utilizaram o estiolamento de partes dos ramos no enraizamento de estacas de goiabeira serrana (Feijoa sellowiana Berg.), obtendo um incremento significativo na percentagem de estacas enraizadas, quando parte dos ramos foi estiolada por 60 dias. Os melhores resultados foram obtidos sem o uso de auxina. Foi observado um efeito fitotóxico na aplicação de IBA nas concentrações utilizadas, uma vez que a percentagem de enraizamento decresceu com o aumento da aplicação de auxina. Os autores atribuíram este fato à elevação da auxina endógena dos tecidos, provocada pelo estiolamento.

Voltolini \& Fachinello (1997) observaram a aplicação do IBA teve efeito antagônico à formação de raízes adventícias em estacas de araçazeiro amarelo (Psidium cattleyanum Sabine) retiradas de plantas matrizes sob sombreamento de 30,50 e $70 \%$.

French (1990) estudando estacas retiradas de plantas de Rhododendron cultivadas em condição de $80 \%$ de sombreamento, observou que as mesmas apresentaram nos tecidos externos ao câmbio concentrações mais elevadas de 
carboidratos que nos tecidos internos. Entretanto estas estacas não apresentaram diferença significativa na percentagem de enraizamento quando comparadas com estacas retiradas de matrizes em pleno sol.

Heller et al. (1994) constataram que o sombreamento moderado das plantas matrizes, da ordem de $50 \%$, proporcionou $90 \%$ de enraizamento de estacas da ornamental Coleonema aspalathoides, enquanto que estacas oriundas de matrizes em condições normais de luminosidade apresentaram $30 \%$ de enraizamento. Os autores concluíram que porcentagens mais elevadas de sombreamento, 75 e $87,5 \%$, apresentaram resultados inferiores devido a menor quantidade de carboidratos nas estacas proporcionada pela diminuição na atividade fotossintética.

\subsubsection{Substrato}

O substrato para enraizamento de estacas pode ser considerado parte integrante do sistema de propagaçáo. Deve manter a estaca no lugar durante o período de enraizamento, proporcionar a manutenção da umidade, permitir a penetração das raízes e as trocas gasosas, e criar um ambiente escuro na base da estaca (Janick, 1966). Além disso, o substrato deve possuir pH adequado para o desenvolvimento radicular, ser livre de patógenos, ter custo acessivel e manter a qualidade das raízes durante a remoção para o transplante (Ruggiero, 1987).

Os materiais devem ser escolhidos de acordo com sua disponibilidade e custo. Componentes orgânicos como turfa, casca de árvore, pó de serra, casca de arroz e esfagno podem ser combinados com escórias, poliestireno, grânulos de argila, e lã de rocha, perlita e vermiculita na porção inorgânica. A porção orgânica tem a função de absorver água e proporcionar porosidade enquanto que a porção inerte visa construir macroporos para melhorar a drenagem (Loach, 1988). 
A aeração e a drenagem do substrato são de grande importância durante a iniciação radicular. Johnson \& Hamilton (1977), observaram que a utilização de areia como substrato proporcionou maior percentagem de estacas enraizadas que sua mistura com turfa $(1: 1, \mathrm{v} / \mathrm{v})$, no enraizamento de Juniperus conferta. Altman \& Freudenberg (1983), relataram um número superior de raízes por estaca de Pelargonium graveolens, quando utilizaram perlita ou turfa:perlita como substrato. Este resultado foi atribuído à melhor aeração e drenagem destes substratos em relação aos outros utilizados.

O tamanho das partículas do substrato também merece importância. Avanzato \& Cherubini (1993), verificando a influência do substrato no enraizamento de micro estacas da macieira 'MM106', obtiveram resultados significativamente superiores ao utilizarem perlita de maior granulação. Tal fato estava relacionado à maior capacidade de retenção de água da perlita de granulação fina, que se mostrou excessiva, prejudicando a aeração.

Embora a aeração, quando comparada ao fornecimento de água, tenha importância secundária em um substrato para enraizamento, as espécies vegetais apresentam diferentes necessidades de ar para o desenvolvimento radicular. $O$ enraizamento de estacas de roseiras é pouco afetado pela baixa aeração, enquanto que as de poinsettia e azaléia apresentaram enraizamento precário (Gislerød, 1982; Gislerød, 1983).

Além das características físicas do substrato, alguns atributos químicos podem interferir no enraizamento de estacas.

Hartmann et al. (1990) atentam para o fato de que materiais com elevada acidez, como a turfa, devem ser misturados com materiais de $\mathrm{pH}$ mais elevado para atingir valores ideais.

Visando verificar o efeito do substrato no enraizamento de estacas da espécie ornamental Epacris impressa, Thompson (1986) utilizou areia, turfa, perlita e vermiculita, tanto isoladamente quanto combinados entre si. As 
combinações entre areia e turfa proporcionaram os melhores resultados, enquanto que a utilização de vermiculita, isoladamente, não foi adequada ao enraizamento de estacas desta planta. $O$ autor também constatou que valores de $\mathrm{pH}$ da ordem de 5,1 favoreceram o enraizamento destas estacas.

O crescimento celular pode ser favorecido em condições de acidez. Rayle \& Cleland (1992) apontam que tecidos vegetais apresentam crescimento semelhante àquele induzido pela auxina, quando expostas a faixa de $\mathrm{pH} 4,5-5,0$, e pouca elongação quando em solução com pH 6,0 - 7,0. Os autores notaram que a presença da auxina reduz o $\mathrm{pH}$ do apoplasto das células em até uma unidade.

Gislerød (1983) observou que o pH ligeiramente acima da neutralidade do substrato lã de rocha, pode ter tido um efeito inibitório no enraizamento de estacas de Poinsettia.

Stimart \& Harbage (1993), estudando o efeito do ácido indolbutírico e do $\mathrm{pH}$ do meio de propagação em microestacas de macieira 'Gala' ( Malus domestica Borkh.), não encontraram interação entre o pH e o IBA, assim como influência do $\mathrm{pH}$ nas características avaliadas. Entretanto, Harbage \& Stimart (1996) em estudos posteriores, demonstraram que a medida que o $\mathrm{pH}$ decrescia, menores quantidades de IBA eram necessárias para provocar um aumento no número de raízes, sendo os melhores resultados obtidos com pH 5,5. Nestas condições a absorção do IBA contido no meio de enraizamento foi maior. 
3. EFEITO DO ESTIOLAMENTO NA PLANTA MATRIZ E DO USO DE ÁCIDO INDOLBUTÍRICO NO ENRAIZAMENTO DE ESTACAS DE GOIABEIRAS. 


\section{EFEITO DO ESTIOLAMENTO NA PLANTA MATRIZ E DO USO DE ÁCIDO INDOLBUTÍRICO NO ENRAIZAMENTO DE ESTACAS DE GOIABEIRAS.}

Walter Henrique da Costa $\mathrm{Jr}^{1}$ e João Alexio Scarpare Filho ${ }^{2}$

RESUMO - Plantas matrizes de goiabeira, dos cultivares Rica e Kumagai, foram submetidas ao estiolamento visando verificar a influência desta técnica no enraizamento de estacas. Adotou-se o delineamento estatístico de blocos ao acaso, em fatorial $2 \times 3$, onde os fatores estudados foram concentração de IBA, em dois níveis ( 0 e $2000 \mathrm{mg} \cdot \mathrm{L}^{-1}$ ), e sombreamento, em três níveis $(0,30$ e 50\%). As estacas foram colocadas para enraizar em câmara de nebulização. Após 60 dias, foram avaliadas a porcentagem de estacas enraizadas, o número de raízes por estaca, a porcentagem de estacas mortas e de estacas com gemas brotadas. Os cultivares testados possuem diferentes capacidades de enraizamento. Para o cultivar Kumagai a utilização de $30 \%$ de sombreamento proporcionou os melhores resultados de enraizamento. Para o cultivar Rica, a utilização de $30 \%$ de sombreamento na planta matriz, ou a aplicação de $2000 \mathrm{mg} \cdot \mathrm{L}^{-1}$ de IBA na estaca, proporcionaram as maiores percentagens de estacas enraizadas. A utilização de ácido indolbutírico aumentou o número de raízes formadas para os 2 cultivares. $O$ estiolamento aumentou o número de raízes formadas para o cultivar Rica, enquanto que para 'Kumagai', não influenciou o número de raízes formadas.

Palavras-chave: Psidium guajava L., sombreamento, IBA, propagação.

\footnotetext{
${ }^{1}$ Eng. Agr. Mestrando em Fitotecnia, ESALQ/USP, Caixa Postal 9, CEP 13418-900, Piracicaba, SP. whcosta@uol.com.br

${ }^{2}$ Eng. Agr., Dr., Professor Doutor do Dep. de Horticultura, ESALQ/USP, Caixa Postal 9, CEP 13418-900, Piracicaba, SP. jascarpa@carpa.ciagri.usp.br
} 


\section{STOCK PLANT SHADING AND INDOLEBUTYRIC ACID EFFECT ON THE ROOTING OF Psidium guajava L.}

Summary - Stock plants of two guava cultivars were submitted to shading with the aim of verifying the technical influence of this technique in the rooting of cuttings. It was used the shading of stock plants with the percentage of 30 and $50 \%$, as stock plants growing with plenty of sun. The cuttings were treated or not with 2000 $\mathrm{mg} \cdot \mathrm{L}^{-1}$ and put to root in green house. After 60 days, the percentage of rooted cuttings were evaluated, as the number of roots per cutting, the percentage of dead cuttings and the percentage of shooted cuttings. The 'Rica' and 'Kumagai' cuttings have different rooting capabilities. The use of $30 \%$ of shading in the 'Kumagai' provided the best results of rooting, but for 'Rica', $30 \%$ shading of stock plants or the application of $2000 \mathrm{mg} . \mathrm{L}-1$ IBA in the cuttings, provided the best percentages of rooting. The use of indolebutyric acid increases the number of roots in the cuttings of both cultivars. Though the shading increases the number of roots for 'Rica' cuttings does not have influence over the number of roots of 'kumagai' cuttings.

Key words: Mirtaceae, guava, IBA, propagation.

\section{INTRODUÇÃO}

A goiabeira é considerada uma espécie de difícil enraizamento, por isso o método tradicionalmente empregado na propagação vegetativa é a enxertia. Entretanto, com o desenvolvimento de sistemas de nebulização tornou-se possivel enraizar estacas que antes eram consideradas muito difíceis ou impossíveis de enraizar. Para isso utilizam-se estacas de ramos com madeira parcialmente madura, e que possuam folhas. Este tipo de estaca, com madeira ainda não lignificada, geralmente enraíza com maior rapidez, porém requer 
equipamentos apropriados, e melhor controle dos fatores que afetam a formação de raízes adventícias. O controle destes fatores, associados à utilização de técnicas como, aplicação exógena de auxinas sintéticas e estiolamento de ramos, podem aumentar a capacidade de enraizamento de estacas caulinares de espécies como a goiabeira.

Pereira et al. (1983) utilizando $2000 \mathrm{mg} \cdot \mathrm{L}^{-1}$ de ácido naftaleno acético (NAA) em estacas herbáceas de goiabeira do cultivar $\mathrm{J}-3$, contendo dois nós e dois pares de folhas, obtiveram $70,22 \%$ de enraizamento em condições de nebulização.

Estudando o efeito do ácido indolbutírico (IBA) no enraizamento de estacas de goiabeira 'Rica' e 'Paluma', Pereira et al. (1991) observaram que as estacas quie receberam aplicação da auxina sintética apresentaram precocidade na iniciação radicular e maior número de raízes.

Kersten \& Ibañez (1993) obtiveram resultados superiores com a utilização de IBA em imersão rápida, em estacas de goiabeira 'Kumagai', quando comparadas com a não utilização desta auxina.

O estímulo ao enraizamento ocorre até uma determinada concentração de auxina, a partir da qual o efeito passa a ser inibitório (Hartmann et al., 1990). Bacarin et al. (1994) constataram que a aplicação de IBA em imersão lenta, na concentração de $100 \mathrm{mg} \cdot \mathrm{L}^{-1}$ proporcionou maior porcentagem de enraizamento às estacas do cultivar Rica, que $200 \mathrm{mg}^{-1}$.

O tipo de auxina sintética utilizada também apresenta influência sobre o enraizamento das estacas. De acordo com Gonzáles \& Schimidt (1992), o NAA apresentou performance significativamente inferior ao do IBA no enraizamento de estacas de goiabeira 'Kumagai'.

O comportamento de estacas de uma mesma espécie pode não ser o mesmo, pois as diferenças muitas vezes ocorrem entre cultivares. Tavares et al. 
(1995) verificaram que estacas retiradas de goiabeiras que produziam frutos vermelhos, apresentavam enraizamento superior, quando comparadas com as de polpa branca.

O estiolamento consiste no crescimento de toda a planta, ou de parte dela, sob condições de ausência total ou parcial da luz. A utilização desta prática como método de enraizamento de estacas não é recente, Gardner (1936) descreveu-o como eficiente para cultivares de macieira difíceis de propagar por estaquia.

O ramos estiolados apresentam diferenças anatômicas que podem favorecer o aparecimento de primórdios radiculares, como uma maior quantidade de células parenquimáticas, e a diminuição das barreiras mecânicas (Hartmann et al., 1990). A formação de tecidos mais tenros, com menor resistência mecânica, se deve a menor presença da lignina, formação de células com paredes mais finas e menor suberização dos tecidos externos. Podem ocorrer também a perda da clorofila e a elongação da região internodal (Maynard \& Bassuk, 1988).

Maynard \& Bassuk (1996) observaram o aparecimento de fendas no anel de esclerênquima de estacas da ornamental Carpirus betulus L. fastigiata, cujas matrizes foram submetidas a 50, 75, 95 e 100\% de estiolamento. O número de fendas aumentou de acordo com 0 incremento na porcentagem de sombreamento.

O estiolamento pode favorecer a ação da auxina, uma vez que torna os tecidos mais sensíveis à ação deste regulador de crescimento (Hartmann et al., 1990). Figueiredo et al. (1995) utilizaram o estiolamento em partes dos ramos de estacas de goiabeira serrana (Feijoa sellowiana Berg.) durante 60 dias, obtendo um incremento significativo na porcentagem de estacas enraizadas. Os melhores resultados foram obtidos sem o uso de auxina. Foi observado um efeito fitotóxico na aplicação de IBA nas concentrações utilizadas, uma vez que a porcentagem de enraizamento decresceu com o aumento da aplicação de auxina. Os autores atribuíram este fato a elevação da auxina endógena dos tecidos, provocada pelo estiolamento. 
Voltolini \& Fachinello (1997) encontraram resultados semelhantes, onde a aplicação do IBA teve efeito antagônico à formação de raízes adventícias em estacas de araçazeiro amarelo (Psidium cattleyanum Sabine) retiradas de plantas matrizes sob sombreamento de 30,50 e $70 \%$.

A diminuição da luminosidade provocada pelo estiolamento pode afetar a síntese de carboidratos de maneiras diferentes. French (1990) estudando estacas retiradas de plantas de Rhododendron cultivadas em condição de $80 \%$ de sombreamento, observou que as mesmas apresentaram nos tecidos externos ao câmbio concentrações mais elevadas de carboidratos que nos tecidos internos. Entretanto estas estacas não apresentaram diferença significativa na porcentagem de enraizamento quando comparadas com estacas retiradas de matrizes em pleno sol.

Heller et al. (1994) constataram que o sombreamento moderado das plantas matrizes, da ordem de $50 \%$, proporcionou $90 \%$ de enraizamento de estacas da ornamental Coleonema aspalathoides, enquanto que estacas oriundas de matrizes em condições normais de luminosidade apresentaram $30 \%$ de enraizamento. Os autores concluíram que porcentagens mais elevadas de sombreamento, 75 e $87,5 \%$, apresentaram resultados inferiores devido a menor quantidade de carboidratos nas estacas proporcionada pela diminuição na atividade fotossintética.

O objetivo do presente trabalho foi verificar o efeito do estiolamento da planta matriz, e sua interação com a utilização de ácido indolbutírico, no enraizamento de dois cultivares de goiabeira.

\section{MATERIAL E MÉTODOS}

As estacas para enraizamento foram obtidas de plantas matrizes das goiabeiras 'Rica', 'Kumagai', que estão localizadas na área experimental do 
Departamento de Produção Vegetal da ESALQ/USP, em Piracicaba (SP). Estas matrizes foram plantadas em 1994, no espaçamento de 7,0m x 7,0m, a partir de mudas obtidas por estaquia. $\mathrm{O}$ solo da área experimental é bastante uniforme e classificado como Terra Roxa Estruturada, eutrófica, A moderado, textura argilosa sobre muito argilosa, profundo e com ausência de pedregosidade.

A goiabeira 'Rica' é originada da variedade Supreme, a partir de semente de polinização aberta, na FCAV-UNESP, em Jaboticabal (SP). Seus frutos apresentam peso variável de 100 a $160 \mathrm{~g}$, com diâmetro entre 6,5 a $8,0 \mathrm{~cm} \mathrm{e}$ transversal de 5,5 a $7,0 \mathrm{~cm}$, com formato ovóide, pescoço curto, e polpa vermelha. Sua principal aptidão é a produção de compotas e polpa (Pereira, 1983).

O cultivar Kumagai foi selecionado por produtores da região de Valinhos (SP), sendo supostamente originário do cruzamento entre o cultivar Australiana e alguma goiabeira local. Apresenta frutos grandes, piriformes, pesando em média 400 a $500 \mathrm{~g}$, com polpa branca e consistente, indicados para o consumo "in natura" (Medina, 1991).

As plantas matrizes foram submetidas pelo período de 14 meses em condições de $30 \%$ e $50 \%$ de sombreamento e em pleno sol. O estiolamento das plantas foi realizado construindo-se, estruturas de madeira com as dimensões de $4,0 \mathrm{~m} \times 4,0 \mathrm{~m} \times 4,0 \mathrm{~m}$, as quais foram completamente cobertas com tela de sombreamento de $30 \%$ ou $50 \%$.

Foram coletados ramos semi-lenhosos, com "madeira verde", sem brotações laterais. À partir de segmentos destes ramos, contendo três nós e um par de folhas inteiras, foram preparadas estacas, de cerca de $20 \mathrm{~cm}$ de comprimento e $0,8 \mathrm{~cm}$ de diâmetro.

Neste experimento foi utilizada, como substrato, a vermiculita, que é o resultado da expansão por aquecimento da mica, sendo portanto estéril. Apresenta densidade muito baixa, de 90 a $150 \mathrm{~kg}$ por $\mathrm{m}^{3}$, tem reação neutra e 
grande capacidade de reter cátions. Absorve de 3 a 4 vezes a sua massa em água , sendo insolúvel neste meio. (Hartmann et al.,1990).

As estacas foram submetidas ao tratamento com (IBA) na concentrações de 0 e $2000 \mathrm{mg}$. $\mathrm{L}^{-1}$, aplicadas em imersão rápida, por um período de 5 segundos. As soluções foram obtidas através da diluição do IBA em álcool $50 \%$.

Utilizaram-se bandejas plásticas, medindo $46,0 \mathrm{~cm} \times 9,0 \mathrm{~cm} \times 28,0 \mathrm{~cm}$, preenchidas com o substrato no qual foram colocadas as estacas. Cada bandeja conteve 3 repetições, de diferentes tratamentos, dispostas a acaso, sendo que cada parcela foi composta por 10 estacas.

Adotou-se o delineamento estatístico de blocos ao acaso, em fatorial $2 \times 3$, onde os fatores estudados foram concentração de IBA, em dois niveis (0 e 2000 $\left.\mathrm{mg} \cdot \mathrm{L}^{-1}\right)$, e sombreamento, em três níveis (0, 30 e 50\%).

As estacas foram mantidas sob nebulização durante o período de enraizamento, em casa de vegetação do Núcleo de Produção de Mudas da CATI, em Tietê (SP). A casa de vegetação é formada por uma estrutura metálica, revestida lateralmente com tela anti-afídeo e com plástico PEBD (Polietileno de baixa densidade) de 150 micra na cobertura.. Esta casa de vegetação conta com o controle de umidade, feito através dos nebulizadores do tipo "fogger" distribuídos uniformemente dentro da estrutura. O sistema de controle de umidade é feito por um sensor colocado na altura das bandejas, e regulado para manter a umidade relativa em $90 \%$.

Após 60 dias avaliou-se o número de estacas enraizadas, o número de raízes por estacas, a porcentagem de mortalidade das estacas e o número de brotações por estaca.

Os dados foram submetidos à análise de variância e as médias comparadas pelo teste de Tukey, ao nível de $5 \%$ de probabilidade. Os dados coletados foram transformados, sendo que utilizou-se arco seno $(x / 100)^{1 / 2}$ para os valores de 
porcentagem de enraizamento e porcentagem de mortalidade das estacas. Os dados de número de raízes e número de estacas brotadas foram transformados de acordo com $(x+0,5)^{1 / 2}$

\section{RESULTADOS E DISCUSSÃO}

Observando a percentagem de enraizamento de estacas enraizadas de goiabeiras 'Rica' e 'Kumagai' (tabelas 1 e 2), verifica-se que a capacidade de enraizamento destes cultivares é diferente. Obteve-se no tratamento controle (0 mg. $\mathrm{L}^{-1}$ de IBA e $0 \%$ de sombreamento), as percentagens de $60 \%$ para 'Rica' enquanto que o cultivar Kumagai apresentou apenas $14,64 \%$ de enraizamento. Pode-se classificar 'Rica' como cultivar mais fácil de enraizar que 'Kumagai'. Este resultado concorda com o encontrado por Tavares et al. (1995), que verificaram que estacas retiradas de goiabeiras que produziam frutos vermelhos apresentaram enraizamento superior, quando comparados com as de polpa branca (Tabelas 1 e 2).

Tabela 1: Efeito do sombreamento e da aplicação de diferentes concentrações de IBA na porcentagem de enraizamento de estacas semi-lenhosas de goiabeira 'Rica'.

\begin{tabular}{cccc}
\hline \multirow{2}{*}{$\%$ Sombreamento } & \multicolumn{2}{c}{ Concentração IBA $\left(\mathrm{mg} \cdot \mathrm{L}^{-1}\right)$} & \multirow{2}{*}{ Médias } \\
\cline { 2 - 3 } & 0 & 2000 & \\
\hline 0 & $60.00 \mathrm{~b} \mathrm{~B}$ & $97.27 \mathrm{a} \mathrm{A}$ & 82.98 \\
30 & $89.71 \mathrm{a} \mathrm{A}$ & $97.27 \mathrm{a} \mathrm{A}$ & 94.06 \\
50 & $75.17 \mathrm{ab} \mathrm{B}$ & $95.35 \mathrm{a} \mathrm{A}$ & 86.96 \\
\hline Médias & 76.08 & 96.69 & \\
\hline
\end{tabular}

As médias seguidas de mesma letra maiúscula na linha e minúscula na coluna não diferem entre si pelo teste de Tukey ao nivel de 5\% de probabilidade. Coeficiente de Variação: $10.751 \%$ 
Tabela 2: Efeito do sombreamento e da aplicação de diferentes concentrações de IBA na porcentagem de enraizamento de estacas semi-lenhosas de goiabeira 'Kumagai'.

\begin{tabular}{cccc}
\hline \multirow{2}{*}{ \% Sombreamento } & \multicolumn{2}{c}{ Concentração IBA $\left(\mathrm{mg} \cdot \mathrm{L}^{-1}\right)$} & \multirow{2}{*}{ Médias } \\
\cline { 2 - 3 } & 0 & 2000 & \\
\hline 0 & $14.64 \mathrm{~b} \mathrm{~B}$ & $57.63 \mathrm{~b} \mathrm{~A}$ & 34.46 \\
30 & $71.09 \mathrm{a} \mathrm{A}$ & $85.35 \mathrm{a} \mathrm{A}$ & 78.66 \\
50 & $56.73 \mathrm{a} \mathrm{A}$ & $50.00 \mathrm{~b} \mathrm{~A}$ & 53.37 \\
\hline Médias & 46.42 & 65.39 & \\
\hline
\end{tabular}

As médias seguidas de mesma letra maiúscula na linha e minúscula na coluna não diferem entre si pelo teste de Tukey ao nível de 5\% de probabilidade. Coeficiente de Variação: $12.844 \%$

Pode ser verificado também que quando se utilizou as estacas retiradas de plantas submetidas ao sombreamento, estas apresentaram comportamento diferenciado daquelas cujas plantas matrizes encontravam-se em pleno sol. Para os cultivares Rica e Kumagai os melhores resultados foram obtidos com estacas de plantas sombreadas em $30 \%$, obtendo-se respectivamente 89,71 e $71,09 \%$ de enraizamento.

O melhor desempenho dessas estacas pode estar relacionado às maiores concentrações de auxinas endógenas nos ramos, provocada pelo sombreamento, conforme proposto por diversos autores (Hartmann et. al. 1990; Voltolini \& Fachinello, 1997)

O sombreamento de $50 \%$, sem a utilização de IBA, influenciou de forma diferente os cultivares. Para o cultivar Kumagai, goiabeira que naturalmente apresenta maior dificuldade de enraizamento de estacas (Gonzales \& Schimidt, 1992), o sombreamento de $50 \%$ apresentou resultado significativamente superior ao controle, embora não apresente diferença estatística significativa do melhor 
resultado, $30 \%$ de sombreamento. Já para o cultivar Rica, $50 \%$ de sombreamento proporcionou um resultado intermediário, não diferindo estatisticamente dos outros tratamentos.

A aplicação de IBA, na concentração de $2000 \mathrm{mg} \cdot \mathrm{L}^{-1}$, aumentou a percentagem de enraizamento dos dois cultivares, quando da utilização de estacas retiradas de plantas desenvolvidas em pleno sol (Tabelas 1 e 2 ). Johnson \& Hamilton (1997) atribuíram o efeito do IBA aos baixos níveis de auxinas endógenas proporcionados pela fotoinativação e pela ação da IAA oxidase, enzima que degrada o ácido indolacético (IAA).

Porém, quando utilizou-se IBA (2000 mg. L $\left.{ }^{-1}\right)$ em estacas retiradas de plantas sombreadas, os cultivares testados tiveram comportamento diferentes.

Para o cultivar Kumagai, a aplicação de IBA não aumentou a percentagem de enraizamento em estacas de ramos crescidos em 30 e $50 \%$ de sombreamento. Para este cultivar, o IBA teve um efeito supressivo nas estacas estioladas em 50 $\%$ de sombreamento, sendo que ficou significativamente inferior à percentagem de estacas enraizadas com $30 \%$ de sombreamento. De acordo com Hartmann et al (1990), o estímulo ao enraizamento ocorre até uma determinada concentração de auxina, à partir da qual o efeito passa a ser inibitório.

A baixa percentagem de enraizamento obtido de estacas estioladas em plantas com $50 \%$ de sombreamento, teoricamente pode estar relacionada à maior disponibilidade de auxinas endógenas. Logo, a maior disponibilidade de auxinas nos tecidos destas estacas, associada à aplicação de $2000 \mathrm{mg} \mathrm{L}^{-1}$ de IBA, podem ter proporcionado a diminuição do enraizamento. Resultados semelhantes foram observados em trabalhos realizados com goiabeira serrana (Figueiredo et al. 1995) e araçazeiro amarelo (Voltolini \& Fachinello, 1997).

Esta teoria porém, não explica os resultados obtidos para o cultivar Rica (Tabela1), que com a aplicação de IBA, aumentou o enraizamento de estacas estioladas com $50 \%$ de sombreamento. Isto sugere que outros fatores devem 
estar relacionados, além das concentrações de auxinas, na performance de enraizamento de estacas estioladas.

Portanto, para o cultivar Kumagai, de difícil enraizamento, o sombreamento de $30 \%$ nas plantas matrizes mostrou ser o melhor tratamento para aumentar a percentagem de estacas enraizadas, enquanto que para o cultivar Rica, de fácil enraizamento, estacas estioladas com $30 \%$ de sombreamento ou aplicação de IBA na concentração de $2000 \mathrm{mg} \cdot \mathrm{L}^{-1}$ apresentaram os melhores resultados. Estes resultados são concordantes com Figueiredo et al. (1995) consideraram desnecessário a utilização de IBA no enraizamento de estacas estioladas de goiabeira serrana.

As tabelas 3 e 4 apresentam as médias de raízes formadas nas estacas para os dois cultivares.

Tabela 3: Efeito do sombreamento e da aplicação de diferentes concentrações de IBA no número de raízes de estacas semilenhosas de goiabeira 'Rica'.

\begin{tabular}{cccc}
\hline \multirow{2}{*}{$\%$ Sombreamento } & \multicolumn{2}{c}{ Concentração IBA $\left(\mathrm{mg} \cdot \mathrm{L}^{-1}\right)$} & \multirow{2}{*}{ Médias } \\
\cline { 2 - 3 } & 0 & 2000 & \\
\hline 0 & 6.34 & 13.94 & $9.79 \mathrm{~b}$ \\
30 & 9.20 & 21.40 & $14.69 \mathrm{ab}$ \\
50 & 12.80 & 19.59 & $16.02 \mathrm{a}$ \\
\hline Médias & $9.27 \mathrm{~B}$ & $18.17 \mathrm{~A}$ & \\
\hline
\end{tabular}

As médias seguidas de mesma letra maiúscula na linha e minúscula na coluna não diferem entre si pelo teste de Tukey ao nível de 5\% de probabilidade. Coeficiente de Variação: $16.407 \%$ 
Tabela 4: Efeito do sombreamento e da aplicação de diferentes concentrações de IBA no número de raízes de estacas semilenhosas de goiabeira 'Kumagai'.

\begin{tabular}{cccc}
\hline \multirow{2}{*}{ \% Sombreamento } & \multicolumn{2}{c}{ Concentração IBA $\left(\mathrm{mg} \cdot \mathrm{L}^{-1}\right)$} & \multirow{2}{*}{ Médias } \\
\cline { 2 - 3 } & 0 & 2000 & \\
\hline 0 & 1.35 & 7.61 & $3.93 \mathrm{a}$ \\
30 & 2.07 & 6.80 & $4.14 \mathrm{a}$ \\
50 & 1.00 & 5.98 & $3.05 \mathrm{a}$ \\
\hline Médias & $1.45 \mathrm{~B}$ & $6.78 \mathrm{~A}$ & \\
\hline
\end{tabular}

As médias seguidas de mesma letra maiúscula na linha e minúscula na coluna não diferem entre si pelo teste de Tukey ao nível de 5\% de probabilidade. Coeficiente de Variação: 15.303\%

Verifica-se que para o cultivar Rica (Tabela 3), tanto o sombreamento das plantas matrizes, como a utilização de IBA, favoreceram a formação de um maior número de raízes. As maiores médias de raízes formadas foram obtidas com sombreamento de 30 e $50 \%$ mais a utilização de IBA. A capacidade do ácido indolbutírico de estimular a formação de raízes em goiabeira já foi verificada por diversos autores (Pereira et al. 1991; Kersten \& Ibañez, 1993; Bacarin et al., 1994), e pode ser vista nas Figuras 1 e 2.

Com relação ao número de raízes formadas em estacas que sofreram estiolamento, a resposta parece estar relacionada com a espécie ou cultivar. Maynard \& Bassuk (1996) verificaram que em estacas de Carpirus betulus, o número de raízes formadas aumentou até a utilização de $75 \%$ de sombreamento. Os autores constataram um maior número de fendas no anel de esclerênquima das estacas estioladas, as quais foram relacionadas ao maior número de raízes formadas. De outra forma, Voltolini \& Fachinello (1997) verificaram que estacas estioladas de araçazeiro amarelo não apresentaram diferenças significativas com relação ao número de raízes formadas, quando submetidas ao sombreamento de $0,30,50$ e $70 \%$. 
Resultados semelhantes a estes, foram obtidos com o cultivar Kumagai (Tabela 4), onde podemos constatar que o estiolamento não provocou aumento na média de raízes formadas. Neste cultivar, somente a utilização de IBA teve influência na quantidade de raízes formadas por estaca.

Ao observarmos as Figuras 1, 2, 3 e 4 podemos constatar que houve diferenças no local de formação de raízes adventícias entre estacas estioladas e não estioladas, nos dois cultivares testados. Nas estacas estioladas as raízes formaram-se quase que exclusivamente na região nodal, enquanto que nas estacas retiradas de plantas crescidas em pleno sol, a formação de raízes ocorreu tanto na região nodal como na internodal. A não formação de raízes na região internodal de estacas estioladas, pode estar relacionada à baixa concentração de carboidratos neste local. Heller et al. (1994) constataram que o sombreamento proporciona diminuição na atividade fotossintética e consequentemente prejudica a síntese de carboidratos, influenciando de forma negativa o enraizamento de estacas.

A concentração de raízes formadas na região nodal de estacas estioladas, pode influenciar na qualidade da muda e consequentemente no desenvolvimento desta no campo, principalmente com relação à fixação no solo. Portanto, sugerese que sejam feitos estudos posteriores para avaliar o desenvolvimento no campo destes tipos de mudas, e seu comportamento com relação à fixação.

A percentagem de estacas mortas, assim como a de estacas brotadas, não foi significativa em nenhum dos tratamentos, para nenhum dos cultivares estudados. 


\section{CONCLUSÃo}

- Os cultivares testados possuem diferentes capacidades de enraizamento.

- Para o cultivar Kumagai a utilização de $30 \%$ de sombreamento proporcionou os melhores resultados de enraizamento.

- Para o cultivar Rica, a utilização de $30 \%$ de sombreamento na planta matriz, ou a aplicação de $2000 \mathrm{mg} \cdot \mathrm{L}^{-1}$ de IBA na estaca, proporcionaram as maiores percentagens de estacas enraizadas.

- A utilização de ácido indolbutírico aumentou o número de raízes formadas para os 2 cultivares.

- O estiolamento aumentou o número de raízes formadas para o cultivar Rica, enquanto que para 'Kumagai', não influenciou o número de raízes formadas. 

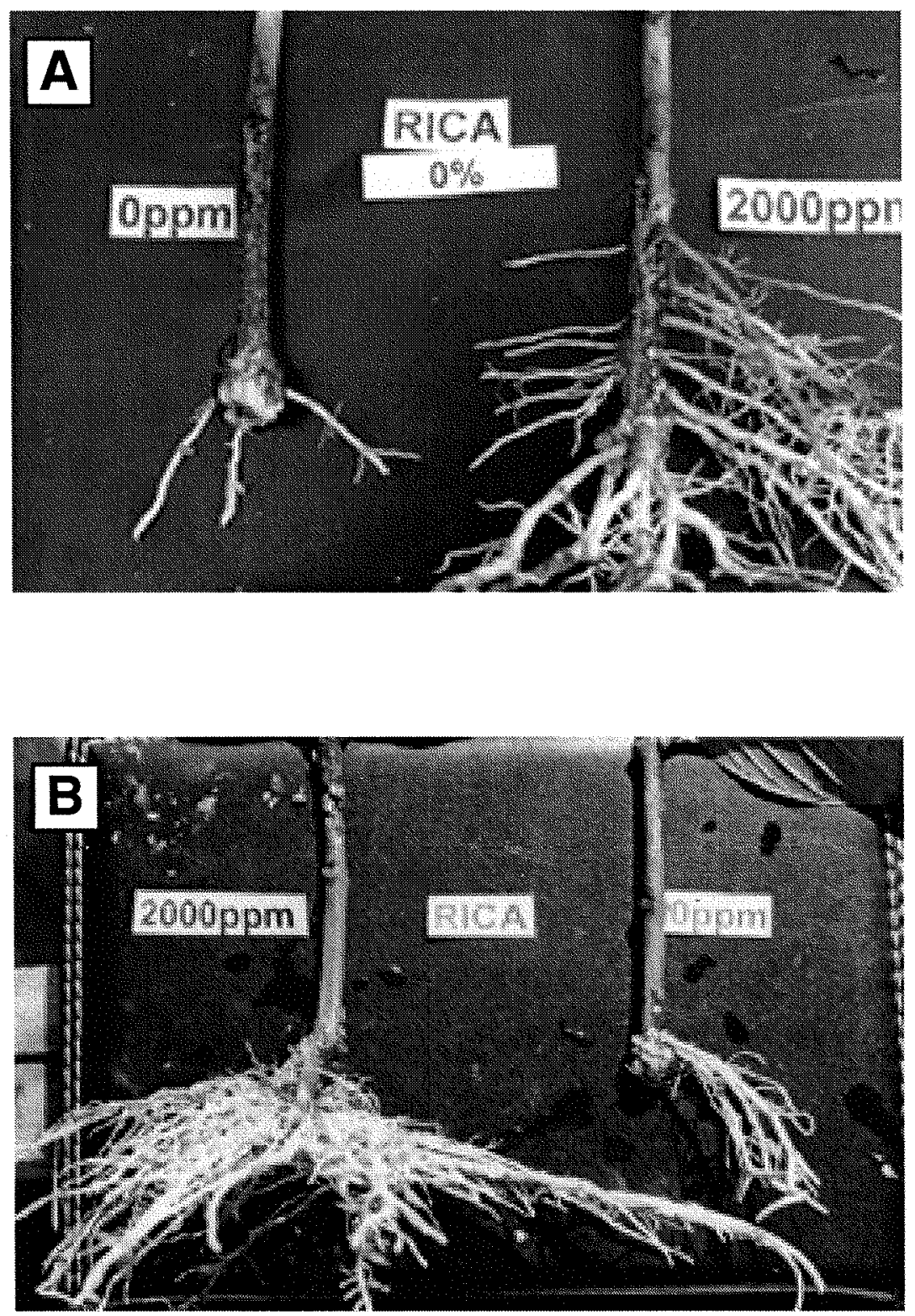

Figura 1. A - Estacas de goiabeira 'Rica' sob $0 \%$ de sombra, tratadas ou não com IBA; B - Estacas de goiabeira 'Rica' sob $50 \%$ de sombra, tratadas ou não com IBA. 

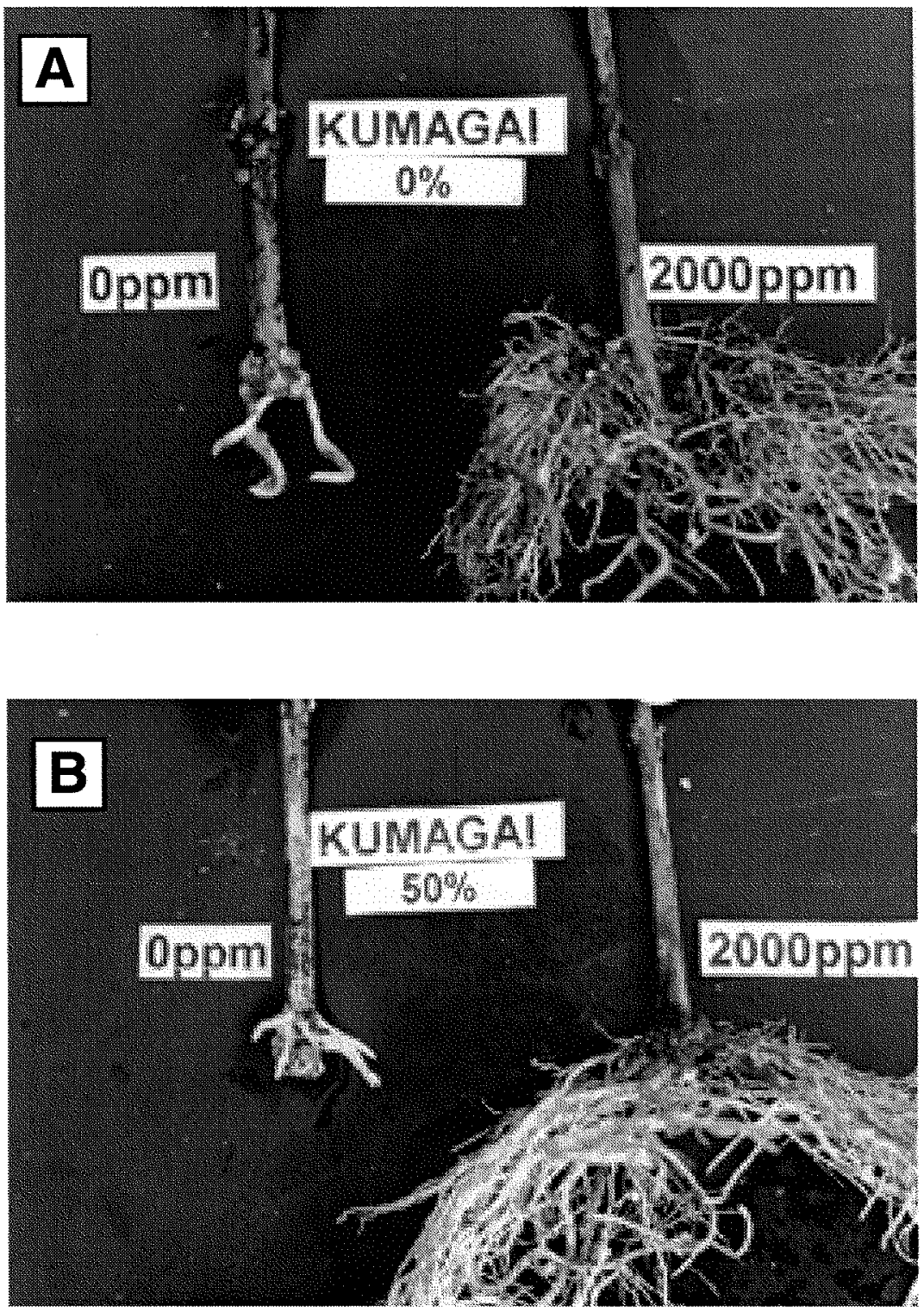

Figura 2. A - Estacas de Goiabeira 'Kumagai' sob $0 \%$ de sombra, tratadas ou não com IBA; B - Estacas de Goiabeira 'Kumagai' sob $50 \%$ de sombra, tratadas ou não com IBA. 


\section{REFERÊNCIAS BIBLIOGRÁFICAS}

BACARIN, M. A.; BENINCASA, M. M. P.; ANDRADE, V. M. M.; PEREIRA, F. M. Enraizamento de estacas aéreas de goiabeira (Psidium guajava L.): Efeito do ácido indolil butírico (AIB) sobre a iniciação radicular. Científica, São Paulo, V.22, n.1, p.71-79, 1994.

FIGUEIREDO, S.L.B.; KERSTEN, E.; SCHUCH, M.W. Efeito do estiolamento parcial e do ácido indolbutírico (IBA) no enraizamento de estacas de ramos de goiabeira serrana (Feijoa sellowiana, Berg). Scientia Agricola, v.52, n.1, p.167-171, 1995.

FRENCH, C.J. Rooting of Rhododendron 'Anna Rose Whitney' as related to stem carbohydrate concentration. HortScience, v.25, n.4, p.409-411, 1990.

GARDNER, F.E. Etiolation as a method of rooting apple variety stem cuttings. Proceedings Americam Society for Horticultural Science, v.34, p.323-329, 1936.

GONZÁLES, M.G.N.; SCHIMIDT, C.A.P. Estudo do efeito de duas concentrações de ácido indol butírico (AIB) e ácido naftaleno acético (ANA) no enraizamento de estacas herbáceas de goiabeira (Psidium guajava L.) cv. Kumagai. . Revista Brasileira de Fruticultura, Cruz das Almas, v.14, n.3, p.229-232, 1992.

HARTMANN, H.T.; KESTER, D. E.; DAVIES,JR, F.T. Plant propagation: principles and pratices. 5. ed. New Jersey :Prentice Hall, 1990.647p.

HELLER, A.; BOROCHOV, A.; HALEVY, A.H. Factors affecting rooting ability of Coleonema aspalathoides. Scientia Horticulturae, v.58, p.335-341, 1994. 
JOHNSON, C.R.; HAMILTON, D.F.; Rooting of Hibiscus rosa-sinensis L. cuttings as influenced by light intensity and ethephon. HortScience, v.12, n.1, p.39-40, 1977.

KERSTEN, E.; IBAÑEZ, U.A. Efeito do ácido indolbutírico (AIB) no enraizamento de estacas de ramos de goiabeira (Psidium guajava L.) em condição de nebulização e teor de aminoácidos totais. Revista Brasileira de Fruticultura, Cruz das Almas, v.15, n.1, p.87-89, 1993.

MAYNARD, B. K. \& BASSUK, N.L. Etiolation and banding effects on adventitious root formation. In: DAVIS, T. D.; HAISSIG, B. E.; SANKHLA, H. (ed.). Adventitious root formation in cuttings.. Portland, Oregon: Dioscorides Press, 1988. cap.2, p. 29-46.

MAYNARD, B. K. \& BASSUK, N.L. Effects of stock plant etiolation, shading, banding, and shoot development on histology and cutting propagation of Carpirus betulus L. fastigiata. Journal of Americam Society for Horticultural Science, v.121, n.5, p.853-860, 1996.

MEDINA, J.C. Cultura. In: MEDINA, J.C.; CASTRO, J.C.; SIGRIST, J.M.M.; KATO, K.; MAIA, M.L.; GARCIA, A.E.B.; LEITE, R.S.S.F. Goiaba: Cultura, matéria prima, processamento e aspectos econômicos. Campinas: ITAL, 1991. cap.1, p.1-120.

PEREIRA, F. M. Rica e Paluma: novas cultivares de goiabeira. Comunicação Técnica. In: CONGRESSO BRASILEIRO DE FRUTICULTURA, 7, Florianópolis - SC, 1983. Anais, p.524-528.

PEREIRA, F. M.; OIOLI, A. A. P.; BANZATTO, D. A. Enraizamento de diferentes tipos de estacas enfolhadas de goiabeira (Psidium guajava L.) em câmaras de nebulização. Científica, São Paulo, V.11, n.2, p.239-44, 1983. 
PEREIRA, F. M.; PETRECHEN, E.H.; BENINCASA, M. M. P.; BANZATTO, D. A. Efeito do ácido indol butírico no enraizamento de estacas herbáceas de goiabeira (Psidium guajava L.) das cultivares 'Rica' e 'Paluma', em câmara de nebulização. Científica, São Paulo, V.19, n.2, p.199-206, 1991.

TAVARES, M. S. W.; KERSTEN, E.; SIEDWERDT, F. Efeitos do ácido indolbutírico e da época de coleta no enraizamento de estacas de goiabeira (Psidium guajava L.) Scientia Agricola, v.52, n.2, p.310-317, 1995.

VOLTOLINI, J.A.; FACHINELLO, J.C. Effect of shading cattley guava stock plant (Psidium cattleyanum Sabine) on propagation by cuttings. Acta Horticulturae, v.452, p.59-62, 1997. 
4. ENRAIZAMENTO DE ESTACAS SEMI-LENHOSAS DE GOIABEIRA ‘KUMAGAl' EM FUNÇÃO DO SUBSTRATO E DO ÁCIDO INDOLBUTÍRICO 


\title{
ENRAIZAMENTO DE ESTACAS SEMI-LENHOSAS DE GOIABEIRA 'KUMAGAl' EM FUNÇÃO DO SUBSTRATO E DO ÁCIDO INDOLBUTÍRICO
}

\author{
Walter Henrique da Costa $\mathrm{Jr}^{3}$ e João Alexio Scarpare Filho ${ }^{4}$
}

RESUMO - O trabalho teve como objetivo verificar a influência do ácido indolbutírico (IBA) e do substrato no enraizamento de estacas semi-lenhosas de goiabeira 'Kumagai' (Psidium guajava L.). As estacas foram submetidas as concentrações de zero, 2000, 4000, e $8000 \mathrm{mg} \cdot \mathrm{L}^{-1}$ de IBA, e colocadas para enraizar em bandejas de plástico contendo turfa, vermiculita ou a mistura turfa:vermiculita (1:1), sob nebulização intermitente. Adotou-se o delineamento estatístico de blocos ao acaso, em fatorial $4 \times 3$, totalizando doze tratamentos. Foram utilizadas três repetições, dos diferentes tratamentos, dispostas a acaso, sendo que cada parcela foi composta por 10 estacas. A concentração de IBA que proporciona maior percentagem de enraizamento para a goiabeira 'Kumagai' varia de acordo com o substrato. Quando utiliza-se turfa como substrato, a maior percentagem de enraizamento é obtida com a utilização de $5565 \mathrm{mg} \cdot \mathrm{L}^{-1}$ de IBA, para vermiculita, o melhor resultado é obtido com a aplicação de $5304 \mathrm{mg} . \mathrm{L}^{-1}$ de IBA, e na mistura turfa e vermiculita, a concentração de $8000 \mathrm{mg} \cdot \mathrm{L}^{-1}$ proporcionou a melhor percentagem de enraizamento. $O$ número médio de raízes por estaca aumentou à medida que aplicou-se uma maior concentração de IBA nas estacas. A aeração e o pH foram atributos dos substratos que influenciaram no enraizamento de estacas.

Palavras-chave: Auxina, propagação, estaquia, Psidium guajava L.

\footnotetext{
${ }^{3}$ Eng. Agr. Mestrando em Fitotecnia, ESALQ/USP, Caixa Postal 9, CEP 13418-900, Piracicaba, SP. whcosta@uol.com.br

${ }^{4}$ Eng. Agr., Dr., Professor Doutor do Dep. de Produçāo Vegetal, ESALQ/USP, Caixa Postal 9, CEP 13418-900, Piracicaba, SP. jascarpa@carpa.ciagri.usp.br
} 


\section{INDOLEBUTYRIC ACID AND ROOTING MEDIA EFFECT ON THE ROOTING OF SEMI-HARDWOOD CUTTINGS OF GUAVA 'KUMAGAl' (Psidium guajava L.)}

Summary - This research has as the main objective to verify the influence of indolebutyric acid and of the substract on the rootting of semi-hardwood 'Kumagai' guava cuttings. The cuttings were submitted to concentrations of zero, 2000, 4000, $8000 \mathrm{mg} \cdot \mathrm{L}^{-1}$ of IBA, and put to root on plastic trays with peat, vermiculite or a peat:vermiculite (1:1) mixture, under intermittent nebulization. After 60 days, the percentage of rooted cuttings were evaluated, as the number of roots per cutting, the percentage of dead cuttings and the percentage of shooted cuttings. The ideal concentration of indolebutyric acid varies according to the substract. Peat, vermiculite and peat:vermiculite (1:1) mixture have the best results with 5565 $\mathrm{mg} \cdot \mathrm{L}^{-1}, 5304 \mathrm{mg} \cdot \mathrm{L}^{-1}$ and $8000 \mathrm{mg} \cdot \mathrm{L}^{-1}$ respectively. The average number of roots increases as the concentration of IBA applied in the cuttings raised. Aeration and $\mathrm{pH}$ were attributes that had influence on the rotting of cuttings.

Key words: Mirtaceae, auxin, propagation media, cuttings. 


\section{INTRODUÇÃO}

A aplicação de auxinas sintéticas é pratica comum no enraizamento de estacas caulinares. Existem vários trabalhos que atestam a influência positiva das auxinas sintéticas, no enraizamento de estacas caulinares de espécies consideradas de difícil enraizamento, como a jaboticabeira (Duarte et al., 1997) e alguns cultivares de pessegueiro (Scarpare Filho, 1990) e de goiabeira (González \& Schimidt , 1992).

Estudando o efeito do ácido indolbutírico (IBA) no enraizamento de estacas de goiabeira dos cultivares Rica e Paluma, Pereira et al. (1991) observaram que as estacas que receberam aplicação de IBA apresentaram precocidade na iniciação radicular e maior número de raízes formadas. Os autores utilizaram a aplicação de IBA em imersão lenta, nas concentrações de $0,100,200$, e 400 $\mathrm{mg} \cdot \mathrm{L}^{-1}$, por um período de 14 horas, e na ausência de luz. Encontraram resultados diferentes para cada um dos cultivares estudadas. A concentração de $200 \mathrm{mg} \cdot \mathrm{L}^{-1}$ mostrou ser a mais eficiente para 'Paluma'. Para o cultivar Rica, os tratamentos com 100 e $200 \mathrm{mg} . \mathrm{L}^{-1}$ apresentaram resultados muito semelhantes. Bacarin et al. (1994) constataram que a aplicação de IBA em imersão lenta, por período variando de 8 a 14 horas e na concentração de $100 \mathrm{mg} \cdot \mathrm{L}^{-1}$, proporcionou maior percentagem de enraizamento em estacas do cultivar Rica.

González \& Schimidt (1992), verificaram a ação do IBA e do ácido naftaleno acético (NAA) no enraizamento de estacas de goiabeira 'Kumagai', nas concentrações de 1000 e $2000 \mathrm{mg}^{-L^{-1}}$ para o IBA e 5 e $10 \%$ para o NAA, observaram que o IBA promoveu o enraizamento de $25 \%$ das estacas na concentração de $1000 \mathrm{mg} \cdot \mathrm{L}^{-1}$, não apresentando diferença significativa em relação a concentração de $2000 \mathrm{mg} \cdot \mathrm{L}^{-1}$. O NAA não proporcionou o enraizamento de nenhuma estaca, nas concentrações utilizadas.

Para Kersten \& Ibañez, (1993), o incremento nas concentrações de IBA proporcionou um aumento significativo da percentagem de enraizamento de 
estacas de goiabeira 'Kumagai'. O tratamento das estacas em imersão rápida nas concentrações de 3000,4000 e $5000 \mathrm{mg}^{-\mathrm{L}^{-1}}$, resultou em $25,0,38,33$ e $47,5 \%$ de enraizamento, respectivamente.

A resposta positiva à aplicação de auxinas sintéticas não é universal, pois Coutinho et al. (1991) ao estudarem a utilização de IBA no enraizamento de estacas semi-lenhosas de diversas espécies de Mirtáceas, observaram que em goiabeira serrana (Feijoa sellowiana Berg.) os resultados obtidos com aplicações de até $5000 \mathrm{mg} \cdot \mathrm{L}^{-1}$ desta auxina foram pouco satisfatórios.

O substrato para enraizamento de estacas pode ser considerado parte integrante do sistema de propagação. Deve manter a estaca no lugar durante o período de enraizamento, proporcionar a manutenção da umidade, permitir a penetração das raízes e as trocas gasosas, e criar um ambiente escuro na base da estaca. $O$ substrato não necessita conter nutrientes, até que as raízes sejam emitidas (Janick, 1966; Loach, 1988). Além disso, o substrato deve possuir pH adequado para o desenvolvimento radicular, ser livre de patógenos, ter custo acessivel e manter a qualidade das raízes durante a remoção para o transplante (Ruggiero, 1987).

Misturas de componentes orgânicos, como a turfa, e ingredientes inertes, como perlita e vermiculita são normalmente usados como substrato. A porção orgânica tem a função de absorver água e proporcionar porosidade enquanto que a porção inerte visa construir macroporos para melhorar a drenagem (Loach, 1988).

A aeração e a drenagem do substrato são de grande importância durante a iniciação radicular. Johnson \& Hamilton (1977), observaram que a utilização de areia como substrato proporcionou maior percentagem de estacas enraizadas que sua mistura com turfa $(1: 1, \mathrm{v} / \mathrm{v})$, no enraizamento de Juniperus conferta. Altman \& Freudenberg (1983), relataram um número superior de raizes por estaca de Pelargonium graveolens, quando utilizaram perlita ou turfa:perlita como substrato. 
Este resultado foi atribuído à melhor aeração e drenagem destes substratos em relação aos outros utilizados.

O tamanho das partículas do substrato também merece importância. Avanzato \& Cherubini (1993), verificando a influência do substrato no enraizamento de micro estacas da macieira 'MM106', obtiveram resultados significativamente superiores ao utilizarem perlita de maior granulação. Tal fato estava relacionado à maior capacidade de retenção de água da perlita de granulação fina, que se mostrou excessiva, prejudicando a aeração.

Embora a aeração, quando comparada ao fornecimento de água, tenha importância secundária em um substrato para enraizamento, as espécies vegetais apresentam diferentes necessidades de ar para o desenvolvimento radicular. (Gislerød, 1982; Gislerød , 1983).

Além das características físicas do substrato, alguns atributos químicos podem interferir no enraizamento de estacas.

Hartmann et al. (1990) atentam para o fato de que materiais com elevada acidez, como a turfa, devem ser misturados com materiais de $\mathrm{pH}$ mais elevado para atingir valores ideais.

Visando verificar o efeito do substrato no enraizamento de estacas da espécie ornamental Epacris impressa, Thompson (1986) utilizou areia, turfa, perlita e vermiculita, tanto isoladamente quanto combinados entre si. As combinações entre areia e turfa proporcionaram os melhores resultados, enquanto que a utilização de vermiculita, isoladamente, não foi adequada ao enraizamento de estacas desta planta. $O$ autor também constatou que valores de $\mathrm{pH}$ da ordem de 5,1 favoreceram o enraizamento destas estacas.

O crescimento celular pode ser favorecido em condições de acidez. Rayle \& Cleland (1992) apontam que tecidos vegetais apresentam crescimento semelhante àquele induzido pela auxina, quando expostas a faixa de $\mathrm{pH} 4,5-5,0$, 
e pouca elongação quando em solução com $\mathrm{pH}$ 6,0 - 7,0. Os autores notaram que a presença da auxina reduz o $\mathrm{pH}$ do apoplasto das células em até uma unidade.

Gislerød (1983) observou que o pH ligeiramente acima da neutralidade do substrato lã de rocha, pode ter tido um efeito inibitório no enraizamento de estacas de Poinsettia.

Stimart \& Harbage (1993), estudando o efeito do ácido indolbutírico e do pH do meio de propagação em microestacas de macieira 'Gala' ( Malus domestica Borkh.), não encontraram interação entre o pH e o IBA, assim como influência do $\mathrm{pH}$ nas características avaliadas. Entretanto, Harbage \& Stimart (1996) em estudos posteriores, demonstraram que a medida que o $\mathrm{pH}$ decrescia, menores quantidades de IBA eram necessárias para provocar um aumento no número de raízes, sendo os melhores resultados obtidos com pH 5,5. Nestas condições a absorção do IBA contido no meio de enraizamento foi maior.

A capacidade de formar raízes adventícias pode variar quando consideramse diferentes espécies vegetais, cultivares, clones e maturação dos tecidos. Dentro das goiabeiras, observa-se que o cultivar Kumagai apresenta dificuldade para ser propagada por estaquia. O presente trabalho tem como objetivo avaliar a influência do substrato e de diferentes concentrações de IBA no enraizamento de estacas semi-lenhosas de goiabeira cultivar Kumagai.

\section{MATERIAL E MÉTODOS}

As estacas foram obtidas de plantas matrizes de goiabeira do cultivar Kumagai, de quatro anos de idade, localizadas na área experimental do Departamento de Produção Vegetal da ESALQ/USP, em Piracicaba (SP). O solo da área é bastante uniforme e classificado como Terra Roxa Estruturada, eutrófica, A moderado, textura argilosa sobre muito argilosa, profundo e com ausência de pedregosidade (Vidal-Torrado \& Sparovek, 1993). O clima de 
Piracicaba, de acordo com a classificação de Köeppen, é do tipo Cwa (tropical de altitude) caracterizado por ter invernos secos e verões chuvosos. Embora possua temperaturas médias de inverno inferiores a $18^{\circ} \mathrm{C}$, as temperaturas dos meses mais quentes (Janeiro e Fevereiro) são superiores a $22^{\circ} \mathrm{C}$, sendo a temperatura média anual igual a $21,1^{\circ} \mathrm{C}$. A deficiência hídrica dos meses secos pode chegar a $19 \mathrm{~mm}$, e a precipitação total ao longo do ano é da ordem de $1253 \mathrm{~mm}$. A altitude do município é de $546 \mathrm{~m}$.

O cultivar Kumagai foi selecionada por produtores da região de Valinhos (SP), sendo supostamente originário do cruzamento entre o cultivar Australiana e alguma goiabeira local. Apresenta frutos grandes, piriformes, pesando em média 400 a $500 \mathrm{~g}$, com polpa branca e consistente, indicados para o consumo "in natura" (Medina, 1991).

Em dezembro de 1998, foram coletados ramos semi-lenhosos, com "madeira verde", sem brotações laterais. À partir de seguimentos destes ramos, contendo três nós e um par de folhas inteiras, foram preparadas estacas, de cerca de $20 \mathrm{~cm}$ de comprimento e $0,8 \mathrm{~cm}$ de diâmetro.

Neste experimento foram utilizados, como substrato, a vermiculita, a turfa e uma mistura contendo volumes iguais de ambos. Algumas características dos substratos encontram-se na Tabela 1. A vermiculita é o resultado da expansão por aquecimento da mica, sendo portanto estéril. Apresenta densidade muito baixa, de 90 a $150 \mathrm{~kg}$ por $\mathrm{m}^{3}$, tem reação neutra e grande capacidade de reter cátions. Absorve de 3 a 4 vezes a sua massa em água, sendo insolúvel neste meio. A turfa é constituída de restos de vegetação aquática e de pântanos, que se preservaram sob a água em estado de decomposição parcial, possuindo uma grande capacidade de retenção de água e elevada acidez (Hartmann te al.,1990). Foram determinadas algumas características físicas e químicas dos substratos, que constam da Tabela 1. 
Tabela 1: Características físicas e químicas dos substratos.

\begin{tabular}{lccc}
\hline Substrato & $\mathrm{pH}$ & Densidade & Capacidade de retenção de água \\
\hline Turfa & 5,3 & $600 \mathrm{~kg} / \mathrm{m}^{3}$ & $150 \%$ \\
Turfa:Vermiculita (1:1) & 6,4 & $290 \mathrm{~kg} / \mathrm{m}^{3}$ & $230 \%$ \\
Vermiculita & 7,2 & $85 \mathrm{~kg} / \mathrm{m}^{3}$ & $500 \%$ \\
\hline
\end{tabular}

As estacas foram tratadas com ácido indolbutírico (IBA) nas concentrações de $0,2000,4000$ e $8000 \mathrm{mg}$. $\mathrm{L}^{-1}$, aplicadas em imersão rápida, por um período de 5 segundos. As soluções foram obtidas através da diluição do IBA em álcool $50 \%$.

Utilizaram-se bandejas plásticas, medindo $46,0 \mathrm{~cm} \times 9,0 \mathrm{~cm} \times 28,0 \mathrm{~cm}$, preenchidas com os diferentes substratos no qual foram colocadas as estacas.

Adotou-se o delineamento estatístico de blocos ao acaso, em fatorial $4 \times 3$, onde os fatores estudados foram concentração de IBA, em quatro níveis $(0,2000$, 4000 e $8000 \mathrm{mg} . \mathrm{L}^{-1}$ ), e substrato, em três níveis (turfa, mistura turfa:vermiculita $1: 1$ e vermiculita), totalizando doze tratamentos. Foram utilizadas três repetições, dos diferentes tratamentos, dispostas a acaso, sendo que cada parcela foi composta por 10 estacas.

As estacas foram mantidas sob nebulização durante o período de enraizamento, em casa de vegetação do Núcleo de Produção de Mudas da CATI, em Tietê (SP). O controle de umidade é feito através dos nebulizadores do tipo "fogger" distribuídos uniformemente dentro da estrutura. O sistema de controle de umidade é feito por um sensor colocado na altura das bandejas, e regulado para manter a umidade relativa em $90 \%$. 
Após 60 dias avaliou-se a percentagem de estacas enraizadas, o número de raízes por estacas, a percentagem de mortalidade e de estacas com gemas brotadas.

Os dados foram submetidos à análise de variância e as médias comparadas pelo teste de Tukey, ao nível de $5 \%$ de probabilidade. Os dados coletados foram transformados, sendo que utilizou-se arco seno $(x / 100)^{1 / 2}$ para os valores de percentagem de enraizamento, mortalidade, e brotação das estacas. Os dados de número de raízes foram transformados de acordo com $(x+0,5)^{1 / 2}$. Foi feita também a regressão polinomial dos dados, visando determinar matematicamente a concentração de IBA que proporciona a maior percentagem de enraizamento, e o maior número de raízes em cada substrato.

\section{RESULTADOS E DISCUSSÃO}

Observando os dados relativos à percentagem de enraizamento verifica-se, de maneira geral, que ocorreu um incremento nestes valores à medida que aumentou-se a concentração do IBA (Tabela 2). Estes resultados corroboram com as afirmações de Blazich (1988) e Hartmann et al. (1990), que destacaram o efeito favorável das auxinas sintéticas na formação de raízes adventícias em diversas espécies.

Os resultados encontrados com a aplicação de $2000 \mathrm{mg} \cdot \mathrm{L}^{-1}$ de IBA $(39,85 \%$, $24,88 \%$ e $30,00 \%$, para turfa, mistura turfa e vermiculita, e vermiculita respectivamente) foram superiores aos encontrados por González \& Schmidt (1992) para a mesma concentração, e utilizando carvão de palha de arroz como substrato.

A influência dos substratos no enraizamento manifestou-se quando foram utilizadas as concentrações de 4000 e $8000 \mathrm{mg} \cdot \mathrm{L}^{-1}$, onde é possível observar 
melhores resultados na utilização da mistura de turfa e vermiculita, que na utilização isolada destes substratos.

Tabela 2: Efeito de diferentes concentrações de IBA e do substrato, na percentagem de enraizamento de estacas semi-lenhosas de goiabeira 'Kumagai'.

\begin{tabular}{cccccc}
\hline \multirow{2}{*}{ Substrato } & \multicolumn{4}{c}{ Concentração de IBA $\left(\mathrm{mg} \cdot \mathrm{L}^{-1}\right)$} & \multirow{2}{*}{ Médias } \\
\cline { 2 - 5 } & 0 & 2000 & 4000 & 8000 & \\
\hline Turfa & $0,00 \mathrm{~b}$ B & 39,85 a A & $50,00 \mathrm{~b}$ A & $50,00 \mathrm{~b} \mathrm{~A}$ & 34,96 \\
$\begin{array}{c}\text { Turfa:Vermiculita } \\
1: 1\end{array}$ & 10,00 a C & 24,88 a B & 83,64 a A & 93,30 a A & 52,95 \\
Vermiculita & 14,76 a C & 30,00 a BC & 60,14 b A & 43,30 b AB & 37,05 \\
\hline Médias & 8,25 & 31,57 & 64,59 & 62,20 & \\
\hline
\end{tabular}

As médias seguidas de mesma letra maiúscula na linha e minúscula na coluna não diferem entre si pelo teste de Tukey ao nível de $5 \%$ de probabilidade. Coeficiente de variação: $12,616 \%$.

Embora a turfa apresente $\mathrm{pH}$ próximo de 5,5, considerado como favorável ao enraizamento (Thompson, 1986) e à absorção do IBA (Harbage \& Stimart, 1996), esta não proporcionou os melhores resultados. Tal fato deve estar relacionado a maior densidade deste substrato, que contribui para uma menor ocorrência de macroporos e consequente drenagem e aeração deficientes. Mainland (1993) também encontrou resultados inferiores quando a turfa foi utilizada como substrato no enraizamento de estacas lenhosas de mirtilo (Vaccinium corymbosum), atribuindo este resultado à drenagem deficiente do substrato, que é prejudicial a aeração.

As maiores porcentagens de enraizamento foram obtidas quando utilizou-se $4000 \mathrm{mg} \cdot \mathrm{L}^{-1}(83,64 \%)$ e $8000 \mathrm{mg} \cdot \mathrm{L}^{-1}(93,30 \%)$ de IBA, na mistura de turfa e vermiculita (Tabela 2). Observa-se que existiu uma interação entre este substrato 
e o uso de IBA, que teve seu efeito potencializado. Este substrato apresenta densidade e retenção de água intermediárias quando comparado aos demais, o que pode ter contribuído para uma melhor aeração durante a iniciação radicular. A importância da aeração nesta fase do enraizamento é destacada por Johnson \& Hamilton (1977) e Altman \& Freudenberg (1983), que observaram maiores porcentagens de enraizamento em substratos com melhor aeração.

A vermiculita é um substrato que possui baixa densidade, boa capacidade de retenção de água associada a porosidade, que lhe confere drenagem adequada. Entretanto, o pH deste substrato $(7,2)$ parece ter influenciado negativamente no enraizamento das estacas. Isto foi observado por Gislerød (1983), utilizando lã de rocha como substrato, onde o $\mathrm{pH}$ ligeiramente acima da neutralidade, pode ter tido um efeito inibitório no enraizamento de estacas de Poinsettia.

Pelo estudo da regressão polinomial, conforme se observa na Figura 1, calculou-se as concentrações que proporcionam as maiores porcentagens de enraizamento, nos diferentes substratos.

Quando utilizou-se turfa, constatou-se que a concentração de IBA que proporciona o enraizamento máximo corresponde a $5565 \mathrm{mg} \cdot \mathrm{L}^{-1}$, sendo que à partir deste ponto o incremento na concentração deste regulador promoveu uma diminuição na percentagem de enraizamento. Comportamento semelhante foi observado na utilização de vermiculita, onde a percentagem máxima de enraizamento foi determinada pela concentração de $5304 \mathrm{mg}^{-1} \mathrm{~L}^{-1}$ de IBA (Figura1). Estes resultados são bastante próximos daquele encontrado por Kersten \& Ibañez, (1993), onde a utilização de $5000 \mathrm{mg}^{-L^{-1}}$ de IBA promoveu o enraizamento de $47,5 \%$ das estacas de goiabeira 'Kumagai', enraizadas em vermiculita, e se encontram dentro do intervalo proposto por Vijay Kumar \& Chauhan (1974), que apontam a faixa entre 4000 e $8000 \mathrm{mg} \cdot \mathrm{L}^{-1}$ de IBA como mais indicada para o enraizamento de estacas de goiabeira.

Entretanto, Marco et al. (1998) encontraram resultados diferentes em estacas de goiabeiras oriundas de um pomar comercial, postas para enraizar em 
vermiculita, onde a concentração correspondente ao número máximo de estacas enraizadas foi de $3068 \mathrm{mg} \cdot \mathrm{L}^{-1}$, que proporcionou $28,02 \%$ de enraizamento. Esta diferença se deve provavelmente ao fato de que a existe diferença na capacidade de enraizamento entre os diferentes materiais genéticos de goiabeira, fato este, verificado por Pereira (1991).

$\mathrm{Na}$ utilização da mistura de turfa e vermiculita verificou-se que concentração de IBA correspondente à maior percentagem de enraizamento encontra-se fora do intervalo estudado (Figura 1). Isto infere que este substrato foi o que apresentou $\mathrm{pH}$ e aeração mais ajustados para o enraizamento deste cultivar, o que proporcionou um maior efeito do regulador vegetal.

A utilização de ácido indolbutírico favoreceu um número de raízes significativamente superior ao controle. Estes resultados corroboram com a afirmação de Preece \& Read (1993) que atribuíram à utilização de reguladores de crescimento a formação de raízes em maior número.

Considerando-se os resultados relativos ao número médio de raízes formadas nas estacas (tabela 3), é possível observar o efeito favorável do IBA sobre esta variável, sendo que a concentração de $8000 \mathrm{mg} \cdot \mathrm{L}^{-1}$ proporcionou a formação de maior número de raízes, diferindo significativamente das demais concentrações. Entretanto, o excesso de raízes formadas neste tratamento implicou na necessidade de realização de desbaste. Isso pode prejudicar a operação de transplante em escala comercial. $\mathrm{Na}$ concentração $4000 \mathrm{mg}^{-\mathrm{L}^{-1}}$ não houve necessidade de desbaste, embora tenha proporcionado uma menor $\%$ de enraizamento.

A percentagem de estacas mortas, assim como a de estacas brotadas, não foi significativa em nenhum dos tratamentos. 
Tabela 3: Efeito de diferentes concentrações de IBA e do substrato no número de raízes de estacas semi-lenhosas de goiabeira 'Kumagai'.

\begin{tabular}{|c|c|c|c|c|c|}
\hline \multirow{2}{*}{ Substrato } & \multicolumn{4}{|c|}{ Concentração de IBA $\left(\mathrm{mg} \cdot \mathrm{L}^{-1}\right)$} & \multirow{2}{*}{ Médias } \\
\hline & 0 & 2000 & 4000 & 8000 & \\
\hline Turfa & $0,00 \mathrm{~b} \mathrm{C}$ & $2,95 \mathrm{~b} \mathrm{~B}$ & 4,60 b B & 17,31 a $A$ & 6,21 \\
\hline $\begin{array}{c}\text { Turfa:Vermiculita } \\
\qquad 1: 1\end{array}$ & $1,00 \mathrm{~b} \mathrm{C}$ & 6,11 a $B$ & $7,08 a b B$ & 11,77 b A & 6,49 \\
\hline Vermiculita & 2,63 a C & $3,30 \mathrm{~b} \mathrm{C}$ & 8,17 a $B$ & 12,44 b A & 6,63 \\
\hline Médias & 1,21 & 4,12 & 6,62 & 13,84 & \\
\hline
\end{tabular}

As médias seguidas de mesma letra maiúscula na linha e minúscula na coluna não diferem entre si pelo teste de Tukey ao nível de 5\% de probabilidade. Coeficiente de Variação: 10,534\%.

\section{CONCLUSÃO}

Os resultados obtidos no presente trabalho permitiram as seguintes conclusões:

- A concentração de IBA que proporciona maior percentagem de enraizamento para a goiabeira 'Kumagai' varia de acordo com o substrato.

- Quando utiliza-se turfa como substrato, a maior percentagem de enraizamento é obtida com a utilização de $5565 \mathrm{mg} \cdot \mathrm{L}^{-1}$ de IBA nas estacas.

- No caso de se utilizar vermiculita, a maior percentagem de enraizamento é obtida usando-se a concentração de $5304 \mathrm{mg}^{-1} \mathrm{~L}^{-1}$ de IBA nas estacas. 
- Para a mistura turfa e vermiculita, a concentração de $8000 \mathrm{mg} \cdot \mathrm{L}^{-1}$ proporcionou a melhor percentagem de enraizamento.

- O número médio de raízes por estaca aumentou à medida que aplicou-se uma maior concentração de IBA nas estacas.

- A aeração e o pH foram atributos dos substratos que influenciaram no enraizamento de estacas. 
TURFA

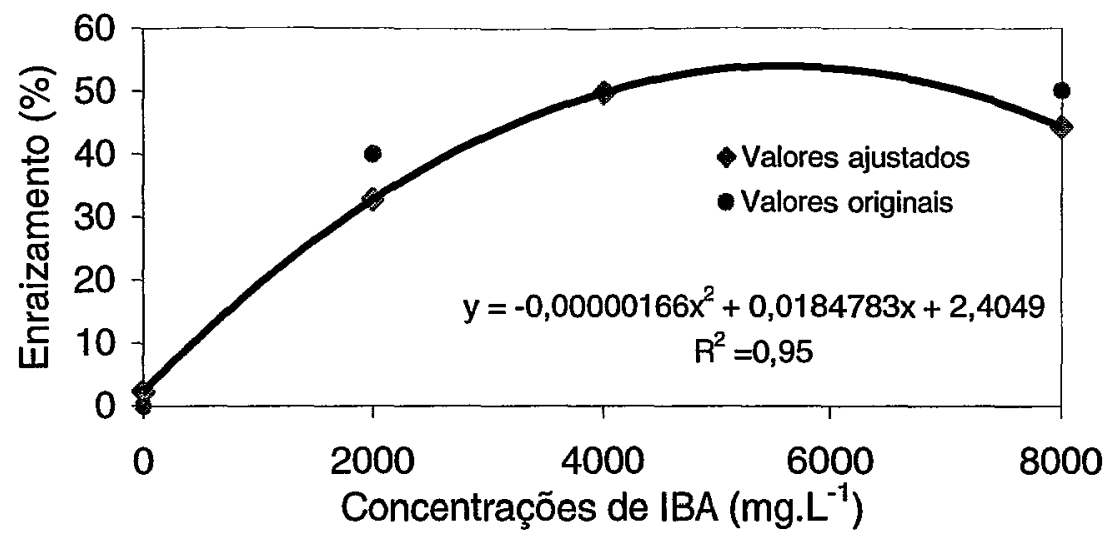

TURFA:VERMICULITA (1:1)

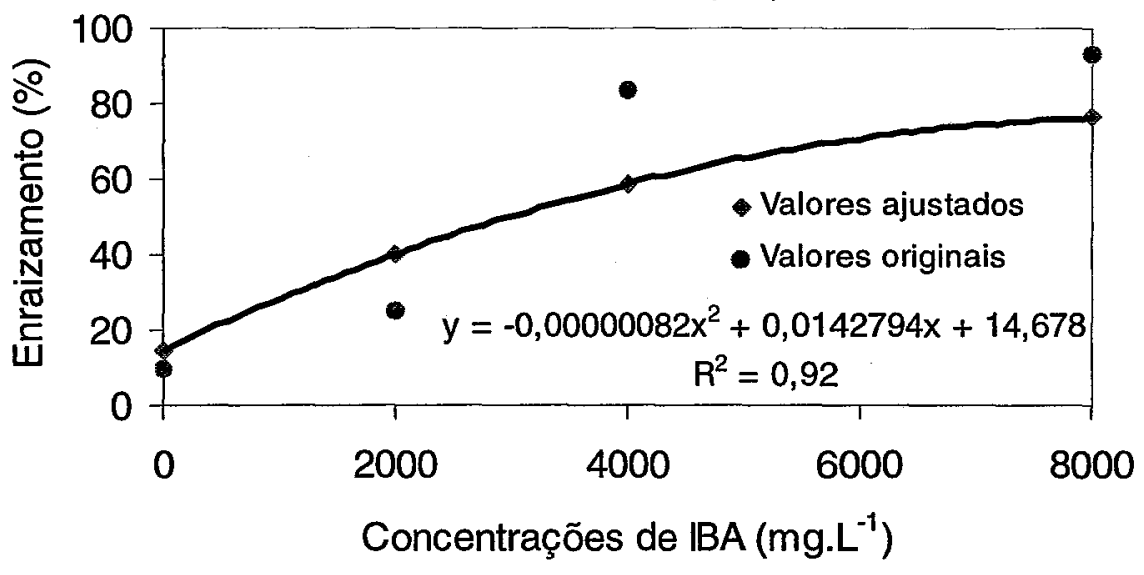

VERMICULITA

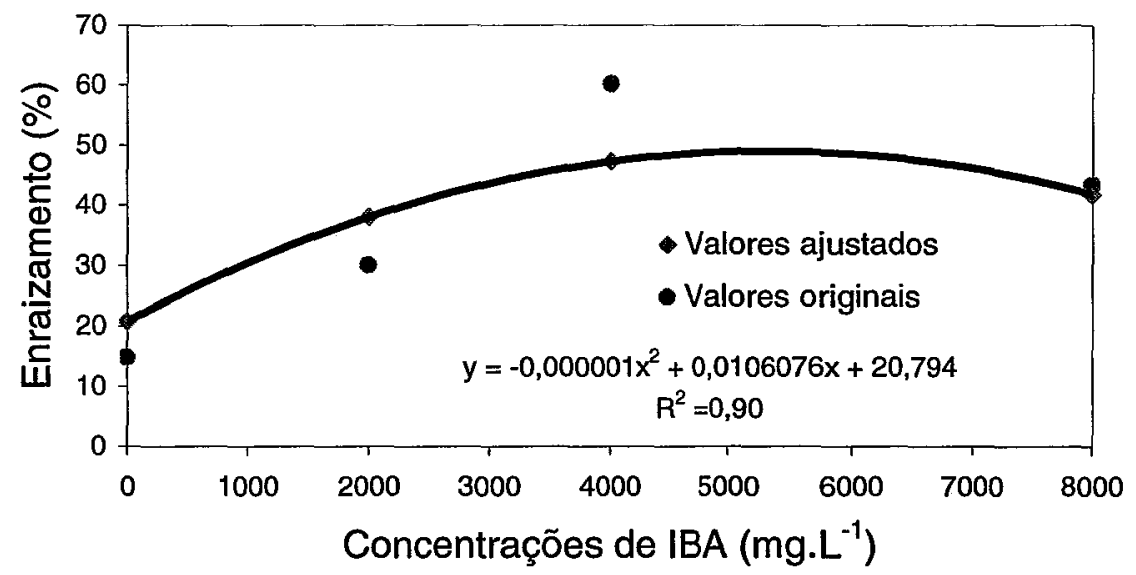

Figura 1. Regressão polinomial dos dados de percentagem de enraizamento, de estacas herbáceas de goiabeira 'Kumagai', em função da concentração de ácido indolbutírico (IBA) em diferentes substratos. 


\section{REFERÊNCIAS BIBLIOGRÁFICAS}

ALTMAN, A.; FREUDENBERG, D. Quality of Pelargonium graveolens cuttings as affected by the rooting medium. Scientia Horticulturae, v.19, p.379-385, 1983.

AVANZATO, D.; CHERUBINI, S. Influence of the substrates on the direct rooting of ex vitro, MM106 apple microcuttings. Acta Horticulturae, n.342, p. 297-302, 1993.

BACARIN, M. A.; BENINCASA, M. M. P.; ANDRADE, V. M. M.; PEREIRA, F. M. Enraizamento de estacas aéreas de goiabeira (Psidium guajava L.): Efeito do ácido indolil butírico (AIB) sobre a iniciação radicular. Científica, v.22, n.1, p.7179, 1994.

BLAZICH, F.A. Chemicals and formulations used to promote adventitious rooting. In: DAVIS, T. D.; HAISSIG, B. E.; SANKHLA, H. (ed). Adventitious root formation in cuttings. Portland: Oregon. Dioscorides Press. 1988. p.132149.

COUTINHO, E.F.; MIELKE, M.S.; ROCHA, M.S.; DUARTE, O.R. Enraizamento de estacas semi-lenhosas de fruteiras nativas da família Myrtaceae com uso do ácido indolbutírico. Revista Brasileira de Fruticultura, v.13, n.1, p.167-171, 1991.

DUARTE, O.; HUETE, M.; LÜDDERS, P. Propagation of jaboticaba (Myrciaria cauliflora (Mart.) Berg). Acta Horticulturae, n.452, p. 123-128, 1997.

GISLERøD, H. R. Physical conditions of propagation media and their influence on the rooting of cuttings. Part 1 . Air content and oxygen diffusion at different moisture tensions. Plant and Soil, v.69, p.445-456, 1982. 
GISLERØD, H. R. Physical conditions of propagation media and their influence on the rooting of cuttings. Part 3 . The effect of air content and temperature in different propagation media on the rooting of cuttings. Plant and Soil, v.75, p.1-14, 1983.

GONZÁLES, M.G.N.; SCHIMIDT, C.A.P. Estudo do efeito de duas concentrações de ácido indol butírico (AIB) e ácido naftaleno acético (ANA) no enraizamento de estacas herbáceas de goiabeira (Psidium guajava L.) Cv. Kumagai. . Revista Brasileira de Fruticultura, v.14, n.3, p.229-232, 1992.

HARBAGE, J.F.; STIMART, D. P. Effect of pH and 1H-indole-3-butyric acid (IBA) on rooting of apple microcuttings. Journal of the American Society for Horticultural Science, v.121, n. 6, p.1049-1053, 1996.

HARTMANN, H.T.; KESTER, D. E.; DAVIES,JR, F.T. Plant propagation: principles and pratices. $5^{\mathrm{a}}$ ed. New Jersey: Prentice Hall, , 1990. 647p.

JANICK, J. A ciência da horticultura. Rio de Janeiro: USAID,1966. 485p.

JOHNSON, C. R.; HAMILTON, D. F. Effects of media and controlled-release fertilizers on rooting and leaf nutrient composition of Junipers conferta and ligustrum japonicum cuttings. Journal of the American Society for Horticultural Science, v.102, n. 3, p.320-322, 1977.

KERSTEN, E.; IBAÑEZ, U.A. Efeito do ácido indolbutírico (AIB) no enraizamento de estacas de ramos de goiabeira (Psidium guajava L.) em condição de nebulização e teor de aminoácidos totais. Revista Brasileira de Fruticultura, v.15, n.1, p.87-89, 1993.

LOACH, K. Water relations and adventitious rooting. In: Adventitious root formation in cuttings, DAVIS, T. D.; HAISSIG, B. E.; SANKHLA, H. ed. Portland, Oregon. Dioscorides Press. p. 102-116. 1988. 
MAINLAND, C. M. Effects of media, grwth stage and removal of lower leaves on rooting of highbush, southern highbush and rabbiteye softwood or hardwood cuttings. Acta Horticulturae, n.346, p.133-140, 1993.

MARCO, C.A.; KERSTEN, E.; da SILVA, J.G.C. Influência do etephon e do ácido indolbutírico no enraizamento de estacas de ramos de goiabeira (Psidium guajava L.). Ciência Rural, v.28, n.2, p.221-224, 1998.

MEDINA, J.C. Cultura. In: MEDINA, J.C.; CASTRO, J.C.; SIGRIST, J.M.M.; KATO, K.; MAIA, M.L.; GARCIA, A.E.B.; LEITE, R.S.S.F. Goiaba: Cultura, matéria prima, processamento e aspectos econômicos. Campinas: ITAL, 1991. Cap.1, p.1-120.

PEREIRA, F.M.; OIOLI, A.A.P.; BANZATTO, D.A. Enraizamento de diferentes tipos de estacas enfolhadas de goiabeira (Psidium guayava L.) em câmaras de nebulização. Científica, v.11, n.2, p.239-244, 1983.

PEREIRA, F. M.; PETRECHEN, E.H.; BENINCASA, M. M. P.; BANZATTO, D. A. Efeito do ácido indol butírico no enraizamento de estacas herbáceas de goiabeira (Psidium guajava L.) das cultivares 'Rica' e 'Paluma', em câmara de nebulização. Científica, V.19, n.2, p.199-206, 1991.

PREECE, J.E.; READ, P.E. The Biology of Horticulture. John Wiley \& Sons, New York. 1993. 480 p.

RAYLE, D.L.; CLELAND, R. E. The acid growth theory of auxin-induced cell elongation is alive and well. Plant Physiology, v.99, p. 1271-1274, 1992.

RUGGIERO, C. Maracujá. Ribeirão Preto: Editora Legis Summa, 1987. 246p.

SCARPARE FILHO, J.A. Enraizamento de estacas herbáceas de pessegueiro (Prunus persica (L.) Batsch), sob efeito de reguladores de crescimento, em sistema de nebulização intermitente. Piracicaba, 1990. 50p. Dissertação 
(Mestrado) - Escola Superior de Agricultura "Luiz de Queiroz", Universidade de São Paulo.

STIMART, D. P.; HARBAGE, J. F. Growth of rooted 'Gala' apple microcuttings as influenced by initial adventitious root count. HortScience, v.26, n.6, p.664-666, 1993.

THOMPSON, W.K. Effects os origin, time of collection, auxins and planting media on rooting of Epacris impressa. Scientia Horticulturae, v.30, n.1-2, p. 127134. 1986.

VIDAL-TORRADO, P.; SPAROVEK, G. Mapa pedológico detalhado do Campus “Luiz de Queiroz”, Universidade de São Paulo. Piracicaba: ESALQ, 1993. (Escala 1:10.000)

VIJAY KUMAR, N.; CHAUHAN, K.S. Studies on the role of auxins, inibitors, and rooting promoting co-factors in rooting stem cuttings of guava (Psidium guajava L.). In: International Horticultural Congress, 19., Warszawa, 1974. Proceedings. Warzawa: The International Society for Horticultural Science, 1974, p.482. 


\section{CONCLUSÕES GERAIS}

Os cultivares de goiabeira testados, Kumagai de polpa branca e Rica de polpa vermelha, possuem naturalmente diferentes capacidades de enraizamento.

A utilização de sombreamento influenciou no aumento de estacas enraizadas dos dois cultivares, sendo que as maiores percentagens foram obtidas com a redução de $30 \%$ da luminosidade.

Com relação ao número de raízes por estaca, o sombreamento influenciou os cultivares de maneira diferente. Para o cultivar Rica aumentou o número de raízes formadas, enquanto que não teve influência no cultivar Kumagai.

Outro efeito importante do sombreamento foi verificado com relação ao local de formação das raízes. Nas plantas sombreadas as raízes formaram-se quase que exclusivamente nos nós, enquanto que nas estacas obtidas de plantas sem sombreamento a formação de raízes ocorreu também nos internódios.

A utilização do regulador vegetal IBA influenciou os cultivares tanto na percentagem de estacas enraizadas, assim como no número de raízes por estaca. Para o cultivar Rica, considerado de fácil enraizamento, a utilização de IBA dispensa a técnica de sombreamento. Já para a 'Kumagai' os melhores resultados foram obtidos com $30 \%$ de sombreamento.

A aeração e $\mathrm{o} \mathrm{pH}$ do substrato afetam a eficiência do ácido indolbutírico aplicado em estacas de goiabeira. Para o substrato que teve $\mathrm{pH}$ ácido associado à boa aeração (turfa:vermiculita, 1:1) a eficiência do IBA resultou em maiores percentagens de enraizamento de estacas do cultivar Kumagai.

Nos substratos em que um destes atributos não estava adequado, aeração deficiente ou $\mathrm{pH}$ elevado, a eficiência do ácido indolbutírico foi prejudicada. 


\section{REFERÊNCIAS BIBLIOGRÁFICAS}

ALTMAN, A.; FREUDENBERG, D. Quality of Pelargonium graveolens cuttings as affected by the rooting medium. Scientia Horticulturae, v.19, p.379-385, 1983.

ANDERSEN, A.S. Enviromental influences on adventitious rooting in cuttings of non-woody species. In Jackson, M. B. (Ed.) New root formation in plants and cuttings. London: Martinus Nijhoff Pub, 1986. p. 223-254.

AVANZATO, D.; CHERUBINI, S. Influence of the substrates on the direct rooting of ex vitro, MM106 apple microcuttings. Acta Horticulturae, n.342, p. 297302, 1993.

BACARIN, M. A.; BENINCASA, M. M. P.; ANDRADE, V. M. M.; PEREIRA, F. M. Enraizamento de estacas aéreas de goiabeira (Psidium guajava L.): Efeito do ácido indolil butírico (IBA) sobre a iniciação radicular. Científica, São Paulo, V.22, n.1, p.71-79, 1994.

BEAKBANE, A. B. Structure of the plant stem in relation to adventitious rooting. Nature, London, v.192, p.954-955, 1961.

BIASI, L.A.; POMMER, C.V.; PINO, P.A.G.S. Propagação de porta-enxertos de videira mediante estaquia semi-lenhosa. Bragantia, v.56, n.2, p.367-376, 1997.

BLAZICH, F.A. Chemicals and formulations used to promote adventitious rooting. In: DAVIS, T. D.; HAISSIG, B. E.; SANKHLA, H. (ed.). Adventitious root formation in cuttings. Portland, Oregon. Dioscorides Press. 1988a. p.132149. 
BLAZICH, F.A. Mineral nutrition and adventitious rooting. In: DAVIS, T. D.; HAISSIG, B. E.; SANKHLA, H. (ed.). Adventitious root formation in cuttings. Portland, Oregon. Dioscorides Press. 1988b. p.61-69.

De VIER, C.L.; GENEVE, R.L. Flowering influences adventitious root formation in chrysanthemum cuttings. Scientia Horticulturae, v.70, p.309-318, 1997.

DUARTE, O.; HUETE, M.; LÜDDERS, P. Propagation of jaboticaba (Myrciaria cauliflora (Mart.) Berg). Acta Horticulturae, n.452, p. 123-128, 1997.

EL- NABARAWY, M.A. Effect of some growth co-factors on the rooting process: I. Effect of some amino acids. Annals of Agricultural Science, v.34, n.1, p.15223, 1996. /Resumo em CAB Abstracts CD-ROM, 1995-1996/

FAHN, A. Plant anatomy. 2ed. New York: Pergamon Press. 1974. 611p.

FIGUEIREDO, S.L.B.; KERSTEN, E.; SCHUCH, M.W. Efeito do estiolamento parcial e do ácido indolbutírico (IBA) no enraizamento de estacas de ramos de goiabeira serrana (Feijoa sellowiana, Berg). Scientia Agricola, v.52, n.1, p.167-171, 1995.

FOUAD, M.M.; FAYEK, M.A.; SELIM, H.H.; EL-SAYED, M.E. Rooting of eight olive cultivars under mist. Acta Horticulturae, n. 286, p. 57-60, 1990.

FRENCH, C.J. Rooting of Rhododendron 'Anna Rose Whitney' as related to stem carbohydrate concentration. HortScience, v.25, n.4, p.409-411, 1990.

GARDNER, F.E. Etiolation as a method of rooting apple variety stem cuttings. Proceedings Americam Society for Horticultural Science, v.34, p.323-329, 1936.

GASPAR, T.; HOFINGER, M. Auxin Metabolism during adventitious rooting. In: Adventitious root formation in cuttings, DAVIS, T. D.; HAISSIG, B. E.; SANKHLA, H. ed. Portland, Oregon. Dioscorides Press. p. 117-131. 1988. 
GISLERØD, H. R. Physical conditions of propagation media and their influence on the rooting of cuttings. Part 1 . Air content and oxygen diffusion at different moisture tensions. Plant and Soil, v.69, p.445-456, 1982.

GISLERØD, H. R. Physical conditions of propagation media and their influence on the rooting of cuttings. Part 3 . The effect of air content and temperature in different propagation media on the rooting of cuttings. Plant and Soil, v.75, p.1-14, 1983.

GONZÁLES, M.G.N.; SCHIMIDT, C.A.P. Estudo do efeito de duas concentrações de ácido indol butírico (IBA) e ácido naftaleno acético (ANA) no enraizamento de estacas herbáceas de goiabeira (Psidium guajava L.) cv. Kumagai. . Revista Brasileira de Fruticultura, Cruz das Almas, v.14, n.3, p.229-232, 1992.

HAISSIG, B. E. Metabolic processes in adventitious rooting of cuttings. In: Jackson, M. B. (Ed.) New root formation in plants and cuttings. London: Martinus Nijhoff Pub., 1986. p.141-189.

HANSEN, J. Stock plant lighting and adventitious root formation. Proceedings of the American Society for Horticultural Science, v. 22, n.5, p. 746-749, 1987.

HARBAGE, J.F.; STIMART, D. P. Effect of pH and 1H-indole-3-butyric acid (IBA) on rooting of apple microcuttings. Journal of the American Society for Horticultural Science, v.121, n. 6, p.1049-1053, 1996.

HARBAGE, J.F.; STIMART, D.P.; EVERT, R.F. Anatomy of adventitious root formation in microcuttings of Malus domestica Borkh. "Gala". Journal of the American Society for Horticultural Science, v.118, n.5, p.680-688, 1993.

HARTMANN, H.T.; KESTER, D. E.; DAVIES,JR, F.T. Plant propagation: principles and pratices. New Jersey :Prentice Hall, , 1990. $5^{\mathrm{a}}$ ed. $647 \mathrm{p}$. 
HELLER, A.; BOROCHOV, A.; HALEVY, A.H. Factors affecting rooting ability of Coleonema aspalathoides. Scientia Horticulturae, v.58, p.335-341, 1994.

HOEHNE, F.C. Frutas Indígenas. Secretaria da Agricultura Indústria e Comércio do Estado de São Paulo, Instituto Botânico, Série D, 1946. 88p.

JANICK, J. A ciência da horticultura. Rio de Janeiro: USAID,1966. 485p.

JOHNSON, C. R.; HAMILTON, D. F. Effects of media and controlled-release fertilizers on rooting and leaf nutrient composition of Junipers conferta and ligustrum japonicum cuttings. Journal of the American Society for Horticultural Science, v.102, n. 3, p.320-322, 1977.

KAMALUDDIN, M.; ALI, M. Effects of leaf area and auxin on rooting and growth of rooted stem cuttings of neem. New Forests, v.12, n.1, p. 11-18, 1996. /Resumo em CAB Abstracts CD-ROM, 1995-1996/

KERSTEN, E.; IBAÑEZ, U.A. Efeito do ácido indolbutírico (IBA) no enraizamento de estacas de ramos de goiabeira (Psidium guajava L.) em condição de nebulização e teor de aminoácidos totais. Revista Brasileira de Fruticultura, Cruz das Almas, v.15, n.1, p.87-89, 1993.

$\mathrm{LOACH}, \mathrm{K}$. Controlling environmental conditions to improve adventitious rooting. In: DAVIS, T. D.; HAISSIG, B. E.; SANKHLA, H. (ed.). Adventitious root formation in cuttings. Portland, Oregon. Dioscorides Press. p. 248-273. 1988.

MAIA, M.L.; GARCIA, A.E.B.; LEITE, R.S.S.F. Aspectos econômicos da produção e mercado. In: MEDINA, J.C.; CASTRO, J.C.; SIGRIST, J.M.M.; KATO, K.; MAIA, M.L.; GARCIA, A.E.B.; LEITE, R.S.S.F. Goiaba: Cultura, matéria prima, processamento e aspectos econômicos. Campinas: ITAL, 1991. Cap.4, p.177-224. 
MAYNARD, B. K. \& BASSUK, N.L. Effects of stock plant etiolation, shading, banding, and shoot development on histology and cutting propagation of Carpirus betulus L. fastigiata. Journal of Americam Society for Horticultural Science, v.121, n.5, p.853-860, 1996.

MAYNARD, B. K. \& BASSUK, N.L. Etiolation and banding effects on adventitious root formation. In: DAVIS, T. D.; HAISSIG, B. E.; SANKHLA, H. (ed.). Adventitious root formation in cuttings.. Portland, Oregon. Dioscorides Press. p. 29-46. 1988.

MEDINA, J.C. Cultura. In: MEDINA, J.C.; CASTRO, J.C.; SIGRIST, J.M.M.; KATO, K.; MAIA, M.L.; GARCIA, A.E.B.; LEITE, R.S.S.F. Goiaba: Cultura, matéria prima, processamento e aspectos econômicos. Campinas: ITAL, 1991. Cap.1, p.1-120.

MELETTI, L.M.M.; NAGAI, V. Enraizamento de Estacas de Sete Espécies de Maracujazeiro (Passiflora spp). Revista Brasileira de Fruticultura, v.14, n. 2, p.163-168, 1992.

MOE, R., \& ANDERSEN, A. S. Stock plant enviroment and subsequent adventitious rooting. In: DAVIS, T. D.; HAISSIG, B. E.; SANKHLA, H. (ed.). Adventitious root formation in cuttings. Portland, Oregon. Dioscorides Press. p. 214-234. 1988.

MORINI, S.; LORETI, F.; SCIUTTI, R. Effect of light quality on rooting of 'Leccino' olive cuttings. Acta Horticulturae, n.286, p. 73-76, 1990.

ONO, E.O.; RODRIGUES, J.D. Aspectos da fisiologia do enraizamento de estacas caulinares. Jaboticabal: FUNEP, 1996. 83p.

PEREIRA, F. M.; OIOLI, A. A. P.; BANZATTO, D. A. Enraizamento de diferentes tipos de estacas enfolhadas de goiabeira (Psidium guajava L.) em câmaras de nebulização. Científica, São Paulo, V.11, n.2, p.239-44, 1983. 
PEREIRA, F. M.; PETRECHEN, E.H.; BENINCASA, M. M. P.; BANZATTO, D. A. Efeito do ácido indol butírico no enraizamento de estacas herbáceas de goiabeira (Psidium guajava L.) das cultivares 'Rica' e 'Paluma', em câmara de nebulização. Científica, São Paulo, V.19, n.2, p.199-206, 1991.

PEREIRA, F.M.; OIOLI, A.A.P.; BANZATTO, D.A. Enraizamento de diferentes tipos de estacas enfolhadas de goiabeira (Psidium guayava L.) em câmaras de nebulização. Científica, v.11, n.2, p.239-244, 1983.

PREECE, J.E.; READ, P.E. The Biology of Horticulture. John Wiley \& Sons, New York. 1993. 480 p.

RAYLE, D.L.; CLELAND, R. E. The acid growth theory of auxin-induced cell elongation is alive and well. Plant Physiology, v.99, p. 1271-1274, 1992.

REUVENI, O.; RAVIVI, M. Importance of leaf retention to rooting of avocado cuttings. Journal of the American Society for Horticultural Science, v.106, n.2, p. 127-130, 1981.

RUGGIERO, C. Maracujá. Ribeirão Preto: Editora Legis Summa, 1987. 246p.

SCARPARE FILHO, J.A. Enraizamento de estacas herbáceas de pessegueiro (Prunus persica (L.) Batsch), sob efeito de reguladores de crescimento, em sistema de nebulização intermitente. Piracicaba, 1990. 50p. Dissertação (Mestrado) - Escola Superior de Agricultura "Luiz de Queiroz", Universidade de São Paulo.

STARLING, M.B.L. PRONI: Perspectivas de mercado internacional para produtos irrigados do Nordeste. Belo Horizonte, MG: Fundação João Pinheiro, 1990, 157p.

STIMART, D. P.; HARBAGE, J. F. Growth of rooted 'Gala' apple microcuttings as influenced by initial adventitious root count. HortScience, v.26, n.6, p.664-666, 1993. 
THOMPSON, W.K. Effects os origin, time of collection, auxins and planting media on rooting of Epacris impressa. Scientia Horticulturae, v.30, n.1-2, p. 127134. 1986.

van OVERBEEK, J.; GORDON, S. A.; GREGORY, L. E. Na analysis of the function of the leaf in the process of root formation in cutings. American Journal of Botany, Lancaster, v.33, p.100-107, 1946.

VILANOVA, M.T. Propagación vegetativa del cafeto. Café Salvador, v.29, p.669$681,1959$.

VOLTOLINI, J.A.; FACHINELLO, J.C. Effect of shading cattley guava stock plant (Psidium cattleyanum Sabine) on propagation by cuttings. Acta Horticulturae, v.452, p.59-62, 1997. 